\title{
Polymorphisms in Human Cytomegalovirus gO Exert Epistatic Influences on Cell-Free and Cell-To-Cell Spread, and Antibody Neutralization on gH Epitopes.
}

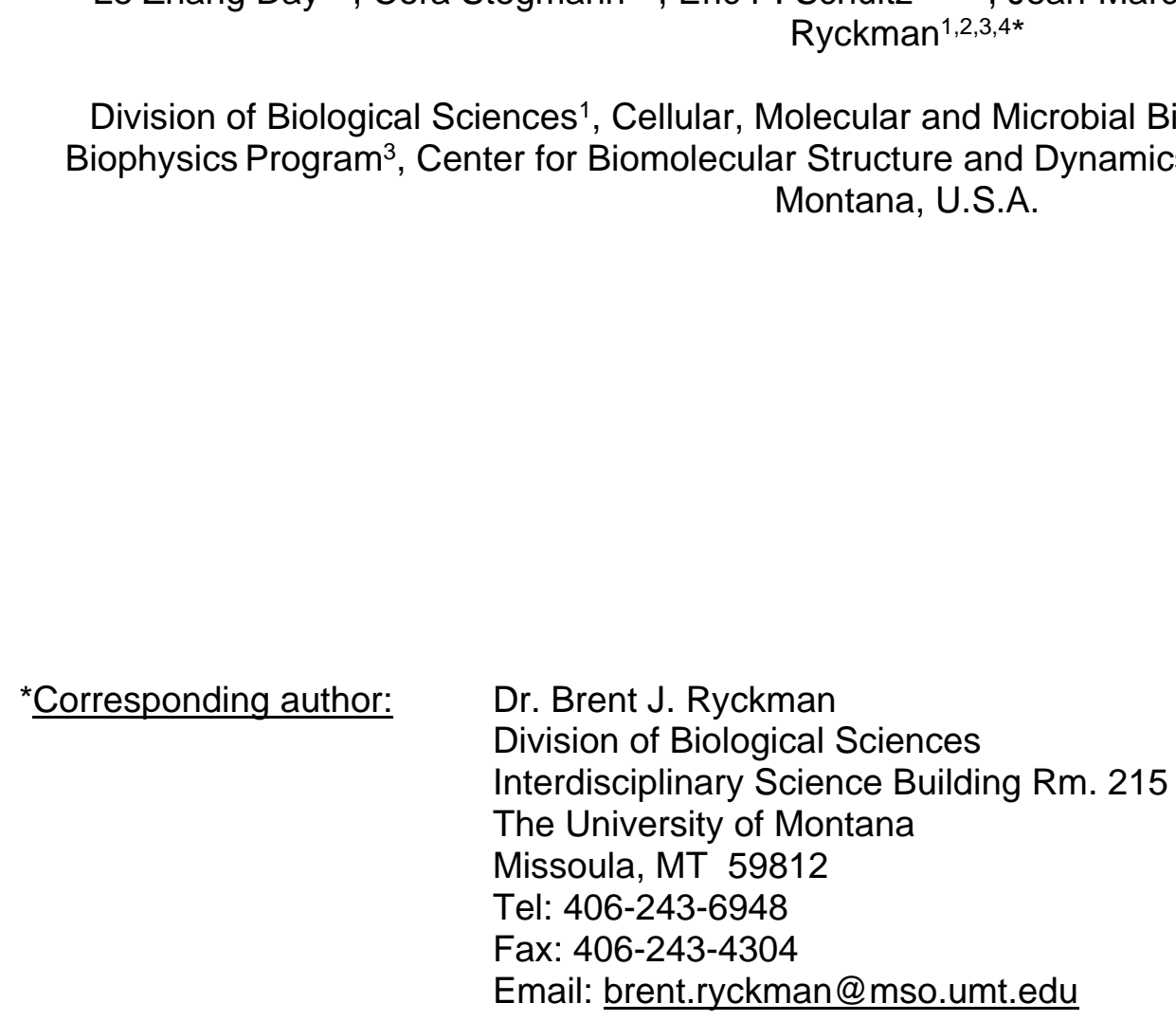
Montana, U.S.A.

${ }^{*}$ Corresponding author: $\quad$ Dr. Brent J. Ryckman

Division of Biological Sciences

Interdisciplinary Science Building Rm. 215

The University of Montana

Missoula, MT 59812

Tel: 406-243-6948

Fax: 406-243-4304

Email: brent.ryckman@mso.umt.edu

Division of Biological Sciences ${ }^{1}$, Cellular, Molecular and Microbial Biology Program ${ }^{2}$, Biochemistry and Biophysics Program ${ }^{3}$, Center for Biomolecular Structure and Dynamics ${ }^{4}$, University of Montana, Missoula,

Running Title: Epistatic effects of HCMV gO polymorphisms 


\section{ABSTRACT}

36 The human cytomegalovirus (HCMV) glycoproteins $\mathrm{H}$ and $\mathrm{L}(\mathrm{gH} / \mathrm{gL})$ can be bound by either $\mathrm{gO}$, or the UL128-

131 proteins to form complexes that facilitate entry and spread and the complexes formed are important targets of neutralizing antibodies. Strains of HCMV vary considerably in the levels of $\mathrm{gH} / \mathrm{gL} / \mathrm{gO}$ and $\mathrm{gH} / \mathrm{gL} / \mathrm{UL} 128-131$ and this can impact infectivity and cell tropism. In this report, we investigated how natural interstrain variation in the amino acid sequence of $\mathrm{gO}$ influences the biology of HCMV. Heterologous gO recombinants were constructed in which 6 of the 8 alleles or genotypes (GT) of gO were analyzed in the backgrounds of strain TR and Merlin (ME). The levels of $\mathrm{gH} / \mathrm{gL}$ complexes were not affected, but there were impacts on entry, spread and neutralization by anti-gH antibodies. AD169 (AD) gO (GT1a) drastically reduced cell-free infectivity of both strains on fibroblasts and epithelial cells. $\mathrm{PHgO}(\mathrm{GT} 2 \mathrm{a})$ increased cell-free infectivity of TR in both cell types, but spread in fibroblasts was impaired. In contrast, spread of ME in both cell types was enhanced by Towne (TN) gO (GT4), despite similar cell-free infectivity. TR expressing TNgO(GT4) was resistant to neutralization by anti-gH antibodies AP86 and 14-4b, whereas ADgO(GT1a) conferred resistance to 14-4b, but enhanced neutralization by AP86. Conversely, ME expressing ADgO(GT1a) was more resistant to $14-4 \mathrm{~b}$. These results suggest; 1) mechanistically distinct roles for $\mathrm{gH} / \mathrm{gL} / \mathrm{gO}$ in cell-free and cell-to-cell spread, 2) gO isoforms can differentially shield the virus from neutralizing antibodies, and 3) effects of gO polymorphisms are epistatically dependent on other variable loci.

\section{IMPORTANCE}

Advances in HCMV population genetics have greatly outpaced understanding of the links between genetic diversity and phenotypic variation. Moreover, recombination between genotypes may shuffle variable loci into various combinations with unknown outcomes. $U L 74(\mathrm{gO})$ is an important determinant of HCMV infectivity, and one of the most diverse loci in the viral genome. By analyzing interstrain heterologous UL74(gO) recombinants, we show that gO diversity can have dramatic impacts on cell-free and cell-to-cell spread as well as on antibody neutralization and that the manifestation of these impacts can be subject to epistatic influences of the global genetic background. These results highlight the potential limitations of laboratory studies of HCMV biology that use single, isolated genotypes or strains. 


\section{INTRODUCTION}

Recent application of state-of-the-art genomics approaches have begun to uncover a greater and more complex genetic diversity of human cytomegalovirus (HCMV) than had been appreciated (1-8). Of the 165

canonical open reading frames (ORFs) in the $235 \mathrm{kbp}$ HCMV genome, 21 show particularly high nucleotide diversity and are distributed throughout the otherwise highly conserved genome. Links between specific genotypes and observed phenotypes are not well understood and as a corollary outcome, the factors driving HCMV genetic diversity and evolution remain speculative. This is further complicated by recombination between genotypes that can shuffle the diverse loci into various combinations, and this may result in epistasis

where the phenotypic manifestation of a specific genotype of one locus may be influenced by the specific genotypes of other loci. Thus, realizing the full potential of modern genomics approaches towards the design of new interventions, clinical assessments and predictions will require better mechanistic understanding of the links between genotypes and phenotypes.

The UL74 ORF codes for glycoprotein $(\mathrm{g}) \mathrm{O}$ and is one of the aforementioned highly diverse loci of HCMV (9-12). Most phylogenetic groupings indicate 8 genotypes or alleles of gO that differ in 10-30\% of amino acids, predominately near the $\mathrm{N}$-terminus and in a short central region. These amino acid polymorphisms also affect predicted $\mathrm{N}$-linked glycan sites. The evolutionary origins of gO genotype diversity

are not understood. Studies that followed infected humans through latency-reactivation cycles over several years demonstrated remarkable stability in $U L 74(\mathrm{gO})$ sequences, arguing against the idea of selective pressure from a dynamically adapting host immune system as a driving force for gO diversity (11, 13). The

functional significance of g0 diversity has only recently been addressed and centers around its role as a

subunit of the envelope glycoprotein complex $\mathrm{gH} / \mathrm{gL} / \mathrm{gO}$, which is involved in the initiation of infection into different cell types.

The general model for herpesvirus entry involves fusion between the virion envelope and cell membranes mediated by the fusion protein $\mathrm{gB}$ and the regulatory protein $\mathrm{gH} / \mathrm{gL}(14-16)$. The $\mathrm{HCMV} \mathrm{gH} / \mathrm{gL}$ can be unbound, or bound by gO or the set of UL128-131 proteins (17-20). How these $\mathrm{gH} / \mathrm{gL}$ complexes participate to mediate infection is complicated and seems to depend on both the cell type and whether the infection is by cell-free virus or direct cell-to-cell spread. Efficient infection of all cultured cell types by cell-free 
cells additionally requires gH/gL/UL128-131 (21-26). Experiments involving HCMV mutants lacking either gO

or UL128-131 suggested that cell-to-cell spread in fibroblast cultures can be mediated by either $\mathrm{gH} / \mathrm{gL} / \mathrm{gO}$ or

$\mathrm{gH} / \mathrm{gL} / \mathrm{UL} 128-131$, whereas in endothelial and epithelial cells $\mathrm{gH} / \mathrm{gL} / \mathrm{UL} 128-131$ is required, and it has

remained unclear whether $\mathrm{gH} / \mathrm{gL} / \mathrm{gO}$ plays any role $(23,25,27,28)$. While it is clear that $\mathrm{gH} / \mathrm{gL} / \mathrm{gO}$ can bind

to the cell surface protein PDGFR $\alpha$ via gO, and that $\mathrm{gH} / \mathrm{gL} / \mathrm{UL} 128-131$ can bind NRP2 and OR14l1 via UL128-

131, the specific function(s) of these receptor engagements is unclear, but may include virion attachment,

regulation of gB fusion activity, or activation of signal transduction pathways (29-31). In the case of

$\mathrm{gH} / \mathrm{gL} / \mathrm{gO}$, binding to PDGFR $\alpha$ activates signaling pathways, but these are not required for entry $(28,30,32)$.

Stegmann et al. showed that binding of a gO null HCMV to fibroblasts and endothelial cells was impaired, yet it

is unclear whether this was due to lack of PDGFRa engagement. (33). Finally, Wu et al. reported

coimmunoprecipitation of $\mathrm{gB}$ with $\mathrm{gH} / \mathrm{gL} / \mathrm{gO}$ and PDGFR $\alpha$, consistent with a role for the $\mathrm{gH} / \mathrm{gL} / \mathrm{gO}-\mathrm{PDGFR} \alpha$

interaction in promoting $\mathrm{gB}$ fusion activity (32). However, unbound $\mathrm{gH} / \mathrm{gL}$ has been shown to mediate cell-cell fusion and has also been found in stable complex with gB in extracts of infected cells and extracellular virions $(20,34)$. Thus, although many of the key factors in HCMV entry and cell-to-cell spread have been identified, their interplay in the various entry pathways is unclear. Moreover, the influence of gO diversity remains a mystery.

The $\mathrm{gH} / \mathrm{gL}$ complexes have been extensively studied as potential vaccine candidates and neutralizing antibodies have been described that react with epitopes on $\mathrm{gH} / \mathrm{gL}$, on UL128-131 and on $\mathrm{gO}$ (35-43). AntiUL128-131 antibodies neutralize with high potency, but only on cell types for which gH/gL/UL128-131 is required for entry; e.g., epithelial cells. In contrast, antibodies that react with epitopes on $\mathrm{gH} / \mathrm{gL}$ tend to neutralize virus on both fibroblasts and epithelial cells, but are far less potent on fibroblasts, where only $\mathrm{gH} / \mathrm{gL} / \mathrm{gO}$ is needed for entry. One explanation for these observations is that $\mathrm{gO}$, with its extensive $\mathrm{N}$-linked glycan decorations presents more steric hindrance to antibodies accessing the underlying $\mathrm{gH} / \mathrm{gL}$ epitopes than do the UL128-131 proteins. Similar effects of glycans in shielding neutralizing epitopes have been described for HIV env, and for HCMV gN (44) (45). In support of this hypothesis for gO, Jiang et al. showed that focal spread of a gO null HCMV in fibroblasts was more sensitive to anti-gH antibodies (46). Recently, Cui et al. described antibodies that reacted to a linear epitope on $\mathrm{gH}$ that exhibited strain-selective neutralization that 
could not be explained by polymorphisms within the $\mathrm{gH}$ epitope (47). One possible explanation was that $\mathrm{gO}$ polymorphisms between the strains imposed differential steric hindrances on these antibodies.

In this study we utilized a set of HCMV BAC-clones that represent the range of phenotypic diversity in terms of $\mathrm{gH} / \mathrm{gL}$ complexes. HCMV TB40/e (TB), TR and Merlin (ME) differ dramatically in the amounts of $\mathrm{gH} / \mathrm{gL}$ complexes in the virion envelope and their infectivity on fibroblasts and epithelial cells. Extracellular virions of TB and TR contain $\mathrm{gH} / \mathrm{gL}$ predominately in the form of $\mathrm{gH} / \mathrm{gL} / \mathrm{gO}$ and are far more infectious on both fibroblasts and epithelial cells than $\mathrm{ME}$, which contains overall lower amounts of $\mathrm{gH} / \mathrm{gL}$, predominately as $\mathrm{gH} / \mathrm{gL} / \mathrm{UL} 128-131(9,26)$. Each of these strains encodes a different representative of the $8 \mathrm{gO}$ genotypes. In a previous report, we demonstrated that variation in the UL74(gO) ORF was not responsible for the observed differences between TR and ME. (48). Rather, it was shown that the amounts of $\mathrm{gH} / \mathrm{gL} / \mathrm{gO}$ in ME and TR virions were influenced by different steady-state levels of gO present during progeny assembly. Kalser et al. showed that replacing the $\mathrm{gO}$ of TB with that of Towne (TN) also did not affect the levels of $\mathrm{gH} / \mathrm{gL}$ complexes but may have enhanced the ability of TB to spread in epithelial cell cultures (49). Here, we have generated a set of heterologous gO recombinants to include 6 of the 8 genotypes in the genetic backgrounds of the $\mathrm{gH} / \mathrm{gL} / \mathrm{gO}$-rich strain TR and the $\mathrm{gH} / \mathrm{gL} / \mathrm{UL} 128-131$-rich $\mathrm{ME}$ to analyze how the differences in $\mathrm{gO}$ sequence influence HCMV biology. The results demonstrate that $\mathrm{gO}$ variation can have dramatic effects on cell-free entry, cell-to-cell spread and the neutralization by anti-gH antibodies. In some cases opposite influences were observed for a given gO genotype in the different backgrounds of TR and ME, indicating epistasis with other genetic differences between these strains.

\section{RESULTS}

Influences of gO polymorphisms on cell-free infectivity and tropism can be dependent on the background strain. To examine the effects of gO polymorphism, a set of recombinant viruses was constructed in which the endogenous UL74(gO) ORFs of strain TR and ME were replaced with the UL74(gO) ORFs from 5 other strains. BAC-cloned strains TR and ME were chosen as the backgrounds for these studies since they represent $\mathrm{gH} / \mathrm{gL} / \mathrm{gO}$-rich and $\mathrm{gH} / \mathrm{gL} / \mathrm{UL} 128-131$-rich strains respectively $(9,26,49)$. Additionally, ME is restricted to a cell-to-cell mode of spread in culture, whereas TR is capable of both cell-free and cell-tocell modes of spread $(23,50,51)$. The intended changes to $U L 74(\mathrm{gO})$ in each recombinant BAC were verified 
by sequencing the UL74 ORF and the flanking regions used for BAC recombineering. However, it was

recently reported that HCMV BAC-clones can sustain various genetic deletions, and rearrangements, and mutations during rescue in fibroblasts or epithelial cells, resulting in mixed genotype populations (52). To ensure that phenotypes characterized were the associated with the intended changes to UL74(gO) and not to other genetic changes sustained during BAC rescue in fibroblasts, all analyses were performed on at least three independently BAC-rescued viral stocks.

As a basis for interpretation of the later biological comparisons among recombinants, the levels of $\mathrm{gH} / \mathrm{gL}$ complexes incorporated into the virion envelope were analyzed by immunoblot as previously described $(9,26)$. As in the previous reports, TR contained predominantly $\mathrm{gH} / \mathrm{gL} / \mathrm{gO}$, whereas $\mathrm{ME}$ contained mostly gH/gL/UL128-131 (Fig 1, compare lane 1 in panels A and B). Propagation of ME under conditions of UL131 transcriptional repression (denoted "Merlin-T" (MT) as described $(26,51)$ ), resulted in more $\mathrm{gH} / \mathrm{gL} / \mathrm{gO}$ and less $\mathrm{gH} / \mathrm{gL} / \mathrm{UL} 128-131$ (Fig. 1C, lane 1). Some minor differences in the amounts of total $\mathrm{gL}, \mathrm{gH} / \mathrm{gL} / \mathrm{gO}$, and $\mathrm{gH} / \mathrm{gL} / \mathrm{UL} 128-131$ were observed for some of the heterologous $\mathrm{gO}$ recombinants relative to their parental strains. However, band density analyses showed that all apparent differences were less than 3-fold and few reached statistical significance when compared across multiple experiments, likely reflecting the limitations of immunoblot as a precise quantitative method, as well as stock-to-stock variability in glycoprotein composition (Table 1). Thus, consistent with our previous report, differences between strains TR and ME in the abundance of $\mathrm{gH} / \mathrm{gL}$ complexes are predominately influenced by genetic background differences outside the UL74(gO) ORF (48).

While $\mathrm{gH} / \mathrm{gL} / \mathrm{gO}$ is clearly important for entry into both fibroblasts and epithelial cells, the mechanisms are likely different since 1) fibroblasts clearly express the $\mathrm{gH} / \mathrm{gL} / \mathrm{gO}$ receptor PDGFR $\alpha$ on their surface, whereas ARPE19 epithelial cells express little or none of this protein $(28,30,32,53)$, and 2) entry into epithelial cells requires $\mathrm{gH} / \mathrm{gL} / \mathrm{UL} 128-131$ in addition to $\mathrm{gH} / \mathrm{gL} / \mathrm{gO}(23,24,26)$. Thus, it was possible that $\mathrm{gO}$ polymorphisms would differentially affect replication in these two cell types. To address this, fibroblast-toepithelial tropism ratios were determined for each parental strain and $\mathrm{gO}$ recombinant by inoculating cultures of fibroblasts and epithelial cells in parallel with equivalent amounts of cell-free virus stocks. The number of infected cells in each culture was then determined by flow cytometry using GFP expressed from the virus genome. Figure 2 shows the results of these experiments as the fold preference for either cell type as a ratio, 
where " 1 " indicates equal infection of both cell types. Stocks of the parental TR were approximately 20 -fold

more infectious on fibroblasts than on epithelial cells (Fig 2A). Preference towards fibroblasts was greater for TR-recombinants expressing $\mathrm{MEgO}(\mathrm{GT5}), \mathrm{PHgO}(\mathrm{GT} 2 \mathrm{~b})$, and TBgO(GT1c). In contrast, tropism ratios of TRrecombinants expressing $\mathrm{ADgO}(\mathrm{GT1a})$ and $\mathrm{TNgO}(\mathrm{GT} 4)$ were closer to 1, indicating more equal infection of both cell types. Parental ME and all of the ME-based gO recombinants had tropism ratios within the range of 6 in favor of fibroblasts to 3 in favor of epithelial cells. Several of these viruses had variability between replicate stocks where some had slight fibroblasts preference and others slight epithelial preference (Fig 2B). Propagation of the ME-based viruses as MT greatly increased the preference towards fibroblasts infection for all recombinants to a range of $30-300$ fold (Fig $2 \mathrm{~B}$ ). These results suggested that for the more $\mathrm{gH} / \mathrm{gL} / \mathrm{gO}$-rich TR and MT, gO polymorphisms may differentially influence the infection of fibroblasts and epithelial cells, shifting the apparent relative tropism. However, such influences were less pronounced for ME, consistent with the low abundance of $\mathrm{gH} / \mathrm{gL} / \mathrm{gO}$ expressed by this virus.

It was not clear if the observed differences in tropism ratios were due to enhanced infection of one cell type, reduced infection of the other cell type or a mixture of both. To address this, specific infectivity (ratio of the number of virions to the number of infectious units) was determined for each parental and recombinant on both fibroblasts and epithelial cells. Multiple independent supernatant stocks of each recombinant were analyzed by qPCR for encapsidated viral genomes and infectious titers on both cell types were determined by flow cytometry quantification of GFP-positive cells (Fig 3). For the TR-based viruses on fibroblasts, MEgO(GT5), TBgO(GT1c), and TNgO(GT4) each resulted in moderately enhanced infectivity (2 to 10-fold fewer genomes/IU) compared to the parental TR, and PHgO(GT2a) enhanced infectivity 30-fold. In contrast, ADgO(GT1a) dropped TR infectivity below the detection limit of the flow cytometry-based assay (Fig 3A, top panel). In our previous report, expression of MEgO in the TR background did not appear to affect infectivity on fibroblasts (48). This discrepancy was likely due to the more sensitive flow cytometry readout used in the current studies as compared to the plaque assay readout used previously. The infectivity of parental TR on epithelial cells was about 20-fold lower than on fibroblasts (i.e., 20-fold higher genomes/IU), but the relative effect of each heterologous gO was similar to that observed on fibroblasts (Fig $3 \mathrm{~A}$, bottom panel). Thus, some of the gO changes had dramatic effects on the infectivity of TR. Although these effects were manifest on both 
cell types, they were more pronounced on fibroblasts and this explains the observed differences in fibroblast preferences reported in Figure 2A.

The infectivity of cell-free ME virions on both cell types was below the detection limit of the flow cytometry-based assay and none of the changes to gO rescued infectivity (Fig 3B). These results indicated that the cell-free virions of all of the ME-based viruses were virtually non-infectious. When propagated as MT, infectivity on both cell types was improved to levels comparable to TR and this was consistent with our previous results (Fig $2 \mathrm{C})(26,48)$. The only significant effect of gO changes on MT was $A D g O(G T 1 a)$, which reduced infectivity on both cell types,. Thus, as in the TR background, some changes to gO influenced infectivity of MT and this was disproportionally manifest on fibroblasts compared epithelial cells, but the overall preference of all of the MT-based viruses was strongly in favor of fibroblasts. In contrast, gO changes had little effect on the infectivity or tropism of ME-based viruses.

It has been reported that gO-null HCMV are impaired for attachment to cells and that soluble $\mathrm{gH} / \mathrm{gL} / \mathrm{gO}$ can block HCMV attachment $(33,54)$. Thus, it was possible that the observed changes to cell-free infectivity due to $\mathrm{gO}$ polymorphisms were related to a role for $\mathrm{gO}$ in attachment. To test this hypothesis, each heterologous gO recombinant was compared to the corresponding parental strain by applying cell-free virus stocks to fibroblast or epithelial cell cultures for approximately $20 \mathrm{~min}$, washing away the unbound virus and then counting the numbers of cell-associated virions by immunofluorescence staining of the capsid-associated tegument protein pp150 (33) (Fig 4 and Tables 2 and 3). Given the short incubation time, high concentrations of input viruses were used to, and these inputs were equal for each set of parental and heterologous gO recombinants within the constraints of the stock concentrations. Higher inputs were required for ME to obtain detectable numbers of bound virus, consistent with the low amounts of $\mathrm{gH} / \mathrm{gL} / \mathrm{gO}$ in these virions. The average number of cell-associated virions per cell varied considerable between experiments, likely reflecting the complex parameters expected to influence virus attachment including stock concentration, cell state and variability in the incubation time between experiments. In some cases, a given recombinant was significantly different from parental in only one or two of the three experiments. It was concluded that these specific gO isoforms did not affect binding or attachment of HCMV to cells. However, binding of TR_TNgO(GT4) and MT_ADgO(GT1a) were each significantly lower than their respective parental viruses in all three experiments on both fibroblasts and epithelial cells. While it was possible that the reduced binding of MT_ADgO(GT1a) was 
227

228

229

230

231

232

233

234

235

236

237

238

239

240

241

242

243

244

245

246

247

248

249

250

251

252

253

254

due in part to the slightly lower amounts of $\mathrm{gH} / \mathrm{gL} / \mathrm{gO}$ (Fig 1C and Table 1), the reduced binding of

TR_TNgO(GT4) could not be similarly explained since this virus had slightly more $\mathrm{gH} / \mathrm{gL} / \mathrm{gO}$ than the parental

TR (Fig. 1A, Table 1). Moreover, reduced binding may help explain the lower infectivity of MT_ADgO(GT1a)

(Fig 3C), but the poor infectivity of TR_ADgO(GT1a) could not be explained by poor binding, and the reduced binding of TR_TNgO(GT4) did not result in reduction of infectivity (Fig 3A).

In sum, these analyses indicated that; 1) gO polymorphisms can influence the cell-free infectivity of HCMV. In some cases this was independent of any effects on abundance of $\mathrm{gH} / \mathrm{gL} / \mathrm{gO}$ in the virion envelope or binding to cells (e.g. parental TR and TR recombinants harboring MEgO(GT5), TBgO(GT1c), and ADgO(GT1a), had dramatically different infectivity but comparable levels of $\mathrm{gH} / \mathrm{gL} / \mathrm{gO}$ and cell binding). 2) The influence of some gO isoforms was dependent on the background strain (e.g., $\mathrm{PHgO}(\mathrm{GT} 2 \mathrm{a})$ enhanced TR infectivity but did not affect ME or MT and TNgO(GT4) reduced binding of TR but had no effect on binding of ME or MT). 3) While some heterologous gO recombinants had quantitatively different effects on infectivity on fibroblast compared to epithelial cells, these did not change the fundamental fibroblast preferences for either TR or MT. 4) Some of the heterologous gOs did appear to change relative tropism of ME. However, the relevance of tropism ratios for these viruses is questionable since the specific infectivity (genomes/IU) analyses suggested that all ME-based recombinants were noninfectious on either cell type. This was consistent with the highly cell-associated nature of $\operatorname{ME}(50,51)$.

\section{Polymorphisms in gO can differentially influence the mechanisms of cell-free and cell-to-cell}

spread. The analyses described above focused on the cell-free infectivity of HCMV, as indicative of a cell-free mode of spread. Cell-to-cell spread mechanisms are likely important for $\mathrm{HCMV}$, and while $\mathrm{gH} / \mathrm{gL}$ complexes are clearly important for cell-to-cell spread, the mechanisms in these processes are poorly characterized in comparison to cell-free infection. Strains TR and ME are well-suited to compare the effects of gO polymorphisms on cell-free and cell-to-cell spread since ME is mostly restricted to cell-to-cell due to the poor infectivity of cell-free virions but can be allowed to also spread cell-free by propagation as MT, whereas TR can spread by both cell-free and cell-to-cell mechanisms $(23,26,50,51)$.

To compare spread among heterologous gO recombinants, replicate cultures were infected at low multiplicity, and at $12 \mathrm{dpi}$, foci morphology was documented by fluorescence microscopy and the increased number of infected cells was determined by flow cytometry. In fibroblasts cultures, parental TR and MT 
255

256

257

258

259

260

261

262

263

264

265

266

267

268

269

270

271

272

273

274

275

276

277

278

279

280

281

282

showed more diffuse foci compared to the tight, localized focal pattern of parental ME, consistent with the notion that TR and MT spread by both cell-free and cell-to-cell mechanisms whereas ME was restricted to cellto-cell spread (Fig 5A). Quantitatively, spread by parental TR increased the numbers of infected cells 55 -fold over 12 days, whereas spread of TR_MEgO(GT5) and TR_PHgO(GT2a) were significantly reduced (Fig 5B). Spread of ME was slightly reduced by $\mathrm{ADgO}$ (GT1a), but was increased by TNgO(GT4) (Fig 5C). Surprisingly, different effects on spread were observed for MT where TBgO(GT1c) and TNgO(GT4) reduced spread, and $\mathrm{ADgO}(\mathrm{GT} 1 \mathrm{a})$ increased spread.

A number of interesting incongruities were observed when comparing the cell-free infectivity of some gO recombinants on fibroblasts to their respective spread characteristics in fibroblasts; 1 ) Spread of TR_PHgO in fibroblasts was reduced compared to the parental TR (Fig 5B), but the cell-free infectivity of this recombinant was actually better (Fig 3A). Similarly, spread of both MT_TBgO(GT1c) and MT_TNgO(GT4) were reduced in fibroblasts (Fig 5D), but cell-free infectivity of both viruses was comparable to parental MT. 2) Conversely, MT_ADgO(GT1a) spread better in fibroblasts (Fig 5D), but the cell-free infectivity was substantially worse (Fig 3C). Since the efficiency of cell-free spread should depend on both the specific infectivity and the quantities of progeny virus released to the culture supernatants, it was possible that some of these incongruities reflected offsetting differences in the quantity of cell-free virus released as compared to their infectivity. To test this, progeny released from infected fibroblasts into culture supernatants were quantified by qPCR. There were no significant differences in the quantity of progeny released per cell for any of the TR or ME-based recombinants (Fig. 6A, and B). Likewise, all of MT-based recombinants released similar numbers of cell-free progeny except for MT_ADgO(GT1a), which was reduced by approximately 4-fold (Fig. 6C). Thus, the discrepancies between efficiency of spread and cell-free infectivity could not be explained by offsetting differences in the release of cell-free progeny. Rather, these results suggested that gO polymorphisms can differentially influence the mechanisms of cell-free and cell-to-cell spread in fibroblasts. The interpretation that $\mathrm{gH} / \mathrm{gL} / \mathrm{gO}$ can provide a specific function for cell-to-cell spread was supported by the results that expression of ADgO(GT1a) and $\mathrm{TNgO}(\mathrm{GT} 4)$, respectively reduced and increased spread of the strain ME, for which spread is almost exclusively cell-to-cell (Fig 5C).

Spread was also analyzed in epithelial cell cultures. Here, foci of both TR and ME remained tightly localized, suggesting predominantly cell-to-cell modes of spread for both strains in this cell type (Fig. 7A). The 
283

284

285

286

287

288

289

290

291

292

293

294

295

296

297

298

299

300

301

302

303

304

305

306

307

308

309

number of TR-infected cells increased by only 5-6 fold over 12 days compared to approximately 25 -fold for ME

(Fig 7B and C). The low efficiency of spread for TR in epithelial cells compared to ME was documented previously and may relate to the low expression of $\mathrm{gH} / \mathrm{gL} / \mathrm{UL} 128-131$ by TR compared to $\mathrm{ME}(23,26,55)$.

Expression of TNgO(GT4) further reduced TR spread in epithelial cells (Fig 7B). In contrast, ME spread was slightly reduced by $\mathrm{TBgO}(\mathrm{GT} 1 \mathrm{c})$ and $\mathrm{ADgO}(\mathrm{GT} 1 \mathrm{a})$, but nearly doubled by $\mathrm{TNgO}(\mathrm{GT} 4)$. The observed increase in ME spread due to TNgO(GT4) was not attributed to increased release of progeny to the culture supernatants in epithelial cells (Fig 8). Note that spread of MT could not be addressed in epithelial cells, since $\mathrm{gH} / \mathrm{gL} / \mathrm{UL} 128-131$ is clearly required for spread in these cells and its repression would complicate analysis of the contribution of gO polymorphisms (23). Nevertheless, it is clear from these experiments that gO polymorphisms can affect spread in epithelial cells and that this can depend on the background strain. Specifically, TNgO(GT4) reduced TR spread but increased ME spread. This suggested that although $\mathrm{gH} / \mathrm{gL} / \mathrm{UL} 128-131$ is required for efficient cell-to-cell spread in epithelial cells, and may even be sufficient in the case of gO-null $\operatorname{HCMV}(25,27), \mathrm{gH} / \mathrm{gL} / \mathrm{gO}$ may also contribute to the mechanism when present.

Polymorphisms in $\mathrm{gO}$ can affect antibody neutralization on $\mathrm{gH}$ epitopes. The extensive $\mathrm{N}$-linked glycosylation of $\mathrm{gO}$ raised the possibility that $\mathrm{gO}$ could present steric hindrance to the binding of antibodies to epitopes on $\mathrm{gH} / \mathrm{gL}$, as was shown for $\mathrm{HCMV} \mathrm{gN}$ and also HIV env $(44,45)$. A corollary hypothesis was that such effects might vary with the polymorphisms among gO isoforms. To address this, neutralization experiments were conducted using two monoclonal anti-gH antibodies; 14-4b, which recognizes a discontinuous epitope likely located near the membrane proximal ectodomain of $\mathrm{gH}(35,56)$ and AP86, which binds to a continuous epitope near the N-terminus of $\mathrm{gH}$ (57). Note that these experiments could only be performed with TR- and MT-based recombinants since the cell-free progeny of ME-based viruses were found to be only marginally infectious (Fig 3B).

Parental TR and recombinants encoding $\mathrm{MEgO}(\mathrm{GT}$ ), $\mathrm{PHgO}(\mathrm{GT} 2 \mathrm{a})$ and $\mathrm{TBgO}(\mathrm{GT} 1 \mathrm{c}$ ) were completely neutralized on fibroblasts by mAb 14-4b, whereas TR_ADgO(GT1a) and TR_TNgO(GT4) were significantly resistant (Fig 9A). There was more variability among TR-based recombinants with mAb AP86 (Fig 9B). Here, parental TR could only be neutralized to approximately $40 \%$ residual infection. TNgO(GT4) rendered TR totally resistant to $\mathrm{mAb} A P 86$, and $\mathrm{MEgO}(\mathrm{GT5})$ also significantly protected TR. In contrast, TR_TBgO(GT1c) and TR_ADgO(GT1a) were more sensitive to mAb AP86. On epithelial cells neutralization 
by both antibodies was more potent and complete than on fibroblasts, and there was less variability among gO

recombinants (Fig 9C, and D). This was consistent with the interpretation that both 14-4b and AP86 could bind their epitopes on $\mathrm{gH} / \mathrm{gL} / \mathrm{UL} 128-131$ and that this represented the majority of the observed neutralization on epithelial cells. However, TR_TNgO(GT4) still displayed some reduced sensitivity to both antibodies, suggesting that $\mathrm{gH} / \mathrm{gL} / \mathrm{gO}$ epitopes also contributed to neutralization on epithelial cells.

MT-based recombinants were generally more sensitive to neutralization by $14-4 b$ than were TR-based viruses (compare 14-4b concentrations in Fig 9A and 10A). Strikingly, whereas TNgO(GT4) conferred 14-4b resistance to TR, it did not in MT, and instead ADgO(GT1a) provided resistance to 14-4b (Fig 10A). As was observed for TR-based recombinants, 14-4b neutralization on epithelial cells was less affected by gO polymorphisms (Fig 10B). Note that neutralization of MT-based recombinants by AP86 could not be tested since MEgH harbors a polymorphism in the linear AP86 epitope that precludes reactivity (57). Together, these results indicated that differences among gO genotypes can differentially affect antibody neutralization on $\mathrm{gH}$ epitopes. Moreover, which gO genotype could protect against which antibody depended on the background strain, suggesting the combined effects of $\mathrm{gO}$ polymorphisms and $\mathrm{gH} / \mathrm{gL}$ polymorphisms.

\section{DISCUSSION}

Efficient cell-free infection of most, if not all cell types requires $\mathrm{gH} / \mathrm{gL} / \mathrm{gO}(22,25,26)$. However, the details of the mechanisms, and the distinctions between the roles of $\mathrm{gH} / \mathrm{gL} / \mathrm{gO}$ in cell-free and cell-to-cell spread remain to be clarified. While there are naturally occurring amino acid polymorphisms in each subunit of $\mathrm{gH} / \mathrm{gL} / \mathrm{gO}, \mathrm{gO}$ has the most dramatic variation, with 8 known genotypes (or alleles) that differ between $10-30 \%$ of amino acids (9-12). All isoforms of $\mathrm{gO}$ are predicted to have extensive $\mathrm{N}$-linked glycan modifications and some of the amino acid differences alter the predicted sites. In a previous report, we sought to determine if gO polymorphisms were a factor influencing the different levels of $\mathrm{gH} / \mathrm{gL} / \mathrm{gO}$ and $\mathrm{gH} / \mathrm{gL} / \mathrm{UL} 128-131$ in strains $\mathrm{TR}$ and ME. On the contrary, results suggested that genetic differences outside the UL74(gO) ORF result in more rapid degradation of $\mathrm{gO}$ in the $\mathrm{ME}$-infected cells compared to $\mathrm{TR}$, and this influences the pool of $\mathrm{gO}$ available during progeny assembly (48). Kalser et al. reported that gO polymorphisms could differentially affect multistep replication kinetics in fibroblasts and epithelial cells (49). However, only TB was analyzed as the background and distinctions between effects on cell-free and cell-to-cell spread were unclear. In this report we constructed a matched set of heterologous gO recombinants in the well-characterized, BAC-cloned strains TR 
and ME. Studies included address aspects of cell-free and cell-to-cell spread, cell-type tropism and neutralization by anti-gH antibodies. The results demonstrate that $\mathrm{gO}$ polymorphisms can influence each of these parameters and the effects in some cases were dependent on the genetic background, suggesting a number of possible epistatic phenomena at play.

A commonly used measure to assess the tropism of HCMV strains, isolates and recombinants is the ratio of infection between fibroblasts and other cell types, including epithelial and endothelial cells $(49,55,58$, 59). Expressions of this ratio have varied, but have generally involved a normalization of the epithelial or endothelial infection to that of fibroblasts. Here we similarly determined the infectious titer of each of the parental strains and heterologous gO recombinants on both fibroblasts and epithelial cells and expressed ratios $\geq 1$ (either fibroblasts/epithelial or epithelial/fibroblasts) to indicate the fold cell type preference or tropism of each virus (Fig 2). Both $\mathrm{gH} / \mathrm{gL} / \mathrm{gO}$-rich viruses, $\mathrm{TR}$ and $\mathrm{MT}$, were strongly fibroblast-tropic and some heterologous $\mathrm{gO}$ isoforms enhanced this preference, while others reduced it. In contrast, the $\mathrm{gH} / \mathrm{gL} / \mathrm{UL} 128$ 131-rich virus $\mathrm{ME}$ infected both cell type more equally (ratios closer to 1), and gO polymorphisms had little effect. The limitation of any such measure of relative tropism is that it does not determine whether the virus in question can efficiently infect one cell type in particular, both or neither. Thus, any 2 viruses compared may have the same fibroblast-to-epithelial cell infectivity ratio for completely different reasons. To address this we also compared infectivity on both cell types using a common comparison for all viruses, i.e., the number of virions in the stock as determined by qPCR for DNAse-protected viral genomes in the cell-free virus stocks (Fig 3). This analysis provided a measure of specific infectivity as the number of genomes/IU, where the lower ratio indicates more efficient infection. Whether higher genomes/IU values reflect the presence of greater numbers of bona fide "defective" virions, or a lower probability or efficiency of each viable virion in the stock to accomplish a detectable infection, and whether or how these two possibilities are different is difficult to know for any type of virus. Nevertheless, these analyses provided important insights to the tropism ratios reported. In general, the specific infectivity ratios of the $\mathrm{gH} / \mathrm{gL} / \mathrm{gO}$-rich viruses $\mathrm{TR}$ and $\mathrm{MT}$ in these experiments were in the range of 500-5000 genomes/IU on fibroblasts, but these viruses were approximately 20-100 fold less infectious on epithelial cells, explaining the strong fibroblast preference exhibited by these strains. The effect of most heterologous $\mathrm{gO}$ isoforms was similar on both cell types, but often of larger magnitude on fibroblasts. Thus, while all of the TR and MT-based gO recombinants remained fibroblast tropic, the quantitatively different 
effects on the two cell types influenced the magnitude of fibroblasts preference. Importantly, in no case did the change of $\mathrm{gO}$ affect the fundamental fibroblast preference of either TR or MT. The infectivity of the $\mathrm{gH} / \mathrm{gL} / \mathrm{UL} 128-131$-rich, ME-based viruses on both cell types was undetectable in these assays. Thus, the near neutral fibroblast-to-epithelial tropism ratios of the ME-based viruses seem to reflect an equal inability to infect either cell type and any assertion of a "preference" for either cell type for extracellular ME virions seems spurious.

Binding to PDGFR $\alpha$ through gO is clearly critical for infection of fibroblasts (30). However, while $\mathrm{gH} / \mathrm{gL} / \mathrm{gO}$ is also important for infection of epithelial cells, the literature is conflicted on the expression of PDGFR $\alpha$ and its importance for HCMV infection in epithelial and endothelial cells $(26,28,29,32,33)$. On either cell type, possible mechanisms of $\mathrm{gH} / \mathrm{gL} / \mathrm{gO}$ include facilitating initial attachment to cells, promoting $\mathrm{gB}$ mediated membrane fusion, and signaling though PDGFR $\alpha$ or other receptors. While Wu et al. were able to coimmunoprecipitate $\mathrm{gB}$ with $\mathrm{gH} / \mathrm{gL} / \mathrm{gO}$ and PDGFR $\alpha$, Vanarsdall et al. showed that $\mathrm{gH} / \mathrm{gL}$ without $\mathrm{gO}$ or UL128-131 can directly interact with gB and promote gB-fusion activity $(20,32,34)$. It has also been shown that $\mathrm{gH} / \mathrm{gL} / \mathrm{gO}$ engagement of PDFGR $\alpha$ can elicit signaling cascades, but that this is not required for infection $(28,30,32)$. In contrast, there is evidence that $\mathrm{gH} / \mathrm{gL} / \mathrm{gO}$ can help facilitate initial virion attachment $(33,54)$. In our studies, TNgO(GT4) reduced binding of TR to both fibroblasts and epithelial cells (Fig 4, Tables 2 and 3). However, the reduced binding of TR_TNgO(GT4) did not result in reduced infection of either cell type, and there were other isoforms of $\mathrm{gO}$ that either resulted in increased or decreased infectivity but were not associated with any detectable alteration in binding. Thus, while $\mathrm{gH} / \mathrm{gL} / \mathrm{gO}$ may contribute to initial binding, it is likely involved in other important mechanisms that facilitate infection and these can be influenced by gO polymorphisms. For example, it is possible that polymorphisms in $\mathrm{gO}$ can affect the nature and outcome of PDGFR $\alpha$ engagement. In support of this hypothesis, Stegmann et al. showed that mutation of conserved residues within the $\mathrm{N}$-terminal variable domain of $\mathrm{gO}$ were critical for PDGFR $\alpha$ binding (60). Thus it is conceivable that the variable residues of $\mathrm{gO}$ can alter the architecture of the interaction with PDGFR $\alpha$. Alternatively, it may be that there are other receptors on both cell types for $\mathrm{gH} / \mathrm{gL} / \mathrm{gO}$ and that $\mathrm{gO}$ polymorphisms can affect those interactions. Also, the effects of several specific $\mathrm{gO}$ isoforms observed in the TR-background were not observed in the ME or MT-backgrounds. Possible explanations for the apparent epistasis include not only the differential contributions of polymorphisms in $\mathrm{gH} / \mathrm{gL}$, but also potential differences 
between strains in other envelope glycoproteins, such as $\mathrm{gB}$, or $\mathrm{gM} / \mathrm{gN}$ may influence the relative importance of $\mathrm{gH} / \mathrm{gL} / \mathrm{gO}$ for binding and infection.

The mechanistic distinctions between cell-free and cell-to-cell spread of HCMV are unclear. Spread of ME in both fibroblast, epithelial and endothelial cells is almost exclusively cell-to-cell and this can be at least partially explained by the non-infectious nature of cell-free ME virions (Fig 3) $(27,50,51,55)$. Laib Sampaio et al. showed that inactivation of the UL74(gO)ORF in ME did not impair spread but that a dual inactivation of both $\mathrm{gO}$ and UL128 completely abrogated spread (27). This indicates that $\mathrm{gH} / \mathrm{gL} / \mathrm{UL} 128-131$ is sufficient for cell-to-cell spread in fibroblasts or endothelial cells in the absence of $\mathrm{gH} / \mathrm{gL} / \mathrm{gO}$, and it seems likely that spread in epithelial cells might be similar in this respect. Our finding that various heterologous $\mathrm{gO}$ isoforms can enhance or reduce spread of ME without affecting the cell-free infectivity strongly suggest that while $\mathrm{gH} / \mathrm{gL} / \mathrm{UL} 128-131$ may be sufficient for cell-to-cell spread, $\mathrm{gH} / \mathrm{gL} / \mathrm{gO}$ can modulate or mediate the process, if present in sufficient amounts. In the context of MT, where expression of $\mathrm{gH} / \mathrm{gL} / \mathrm{UL} 128-131$ is reduced to subdetectable levels $(26,51)$ the virus gained cell-free spread capability, and yet some of the heterologous gO isoforms had opposite effects on cell-free infectivity and spread (compare Fig 3C to 5D). Similar discorrelations between cell-free infectivity and spread were observed for the naturally $\mathrm{gH} / \mathrm{gL} / \mathrm{gO}$-rich strain $\mathrm{TR}$, albeit with different heterologous $\mathrm{gO}$ isoforms involved. That $\mathrm{gO}$ polymorphisms can have opposite effects on cell-free and cell-to-cell spread supports a hypothesis of mechanistic differences in how $\mathrm{gH} / \mathrm{gL} / \mathrm{gO}$ mediates the two processes, and again these effects seem dependent on epistatic influences of the different genetic backgrounds.

Beyond the roles of $\mathrm{gH} / \mathrm{gL} / \mathrm{gO}$ in replication, the complex is likely a significant target of neutralizing antibodies, and therefore a valid candidate for vaccine design. Several groups have reported neutralizing antibodies that react with epitopes contained on the $\mathrm{gH} / \mathrm{gL}$ base of both $\mathrm{gH} / \mathrm{gL} / \mathrm{UL} 128-131$ and $\mathrm{gH} / \mathrm{gL} / \mathrm{gO}$ and others that react to $\mathrm{gO}(35-43)$. We found that changing the $\mathrm{gO}$ isoform can have dramatic effects on the sensitivity to two anti-gH mAbs (Figs 9 and 10). In the TR background on fibroblasts, both ADgO(GT1a) and $\mathrm{TNgO}$ (GT4) conferred significant resistance to neutralization by $14-4 \mathrm{~b}$, which likely reacts to a discontinuous epitope near the membrane proximal ectodomain of $\mathrm{gH}(35,56)$. TNgO(GT4) also conferred resistance to AP86, which reacts to a linear epitope near the $\mathrm{N}$-terminus of $\mathrm{gH}$ (57), whereas $\mathrm{ADgO}$ (GT1a) actually increased sensitivity of TR to AP86. Neutralization by either antibody on epithelial cells was not significantly 
affected, consistent with the notion that these antibodies can also neutralize by reacting to $\mathrm{gH} / \mathrm{gL} / \mathrm{UL} 128-131$. Again, the strain background exerted considerable influence over the effects of gO polymorphisms. For MT, it was $\mathrm{ADgO}$ (GT1a) that conferred resistance to $14-4 \mathrm{~b}$, and the other isoforms had little or no effect. The observed effects on neutralization on $\mathrm{gH}$ epitopes likely involve differences in how $\mathrm{gO}$ variable regions or associated glycans fold onto $\mathrm{gH} / \mathrm{gL}$ to exert differential steric effects. Relatedly, the differential influence of $\mathrm{gO}$ isoforms in the two genetic backgrounds suggests epistasis involving the additive effects of gO polymorphisms with the more subtle gH polymorphisms, which together can differentially affect the global conformation of the $\mathrm{gH} / \mathrm{gL} / \mathrm{gO}$ trimer.

Previous analyses have suggested two groups of $\mathrm{gH}$ sequences defined by polymorphisms at the $\mathrm{N}$ terminus, including the AP86 epitope $(57,61)$. Of the strains represented in this study, TB, TR and AD belong to the $\mathrm{gH} 1$ genotype and are sensitive to AP86, whereas $\mathrm{ME}$, TN and $\mathrm{PH}$ belong to $\mathrm{gH} 2$ genotype and are resistant to AP86. The differential effects of gO recombinants reported here raise questions about the combinations of $\mathrm{gH}$ and $\mathrm{gO}$ genotypes in HCMV circulating in human populations. The recently published genome sequence datasets from clinical specimens have been collected with short-read sequencing approaches, which allow sensitive detection of the various $\mathrm{gH}$ and $\mathrm{gO}$ genotypes within samples, but not the combinations of the two ORFs on individual genomes $(1,3,4,6,7)$. To address, this we analyzed 236 complete HCMV genome sequences of isolated strains and BAC clones in the NCBI database (Fig 11). Approximately half the sequences were $\mathrm{gH} 1$ and the other half $\mathrm{gH} 2$. $\mathrm{ADgO}(\mathrm{GT} 1 \mathrm{a})$ and $\mathrm{TBgO}(\mathrm{GT} 1 \mathrm{c})$ genotypes were exclusively linked to $\mathrm{gH} 1$, whereas $\mathrm{MEgO}(\mathrm{GT} 5)$ was exclusively linked to $\mathrm{gH} 2$. Other $\mathrm{gO}$ genotypes were found mixed with both $\mathrm{gH}$ genotypes, but in most cases, disproportionally with one of the $\mathrm{gH}$ genotypes. These analyses agreed with Rasmussen et al who suggested a strong linkage between $\mathrm{gH} 1$ and gO1 genotypes (note that their study predated the GT1a, 1, b, and 1c subdivisions) (10). Thus, it appears that $\mathrm{gH}$ and $\mathrm{gO}$ genotypes are non-randomly linked. This may be due in part to the adjacent position of UL74(gO) and $\operatorname{UL75}(\mathrm{gH})$ on the HCMV genome and the sequence diversity, together limiting the frequency of recombination, as suggested by the high linkage-disequilibrium of this region reported by Lassalle et al (3). In addition, our results may suggest linkage pressures based on functional compatibility of $\mathrm{gH}$ and $\mathrm{gO}$. However, it was worth noting that among the more striking effects reported were the loss of cell-free infectivity and differential sensitivity to neutralization by gH antibodies of TR_ADgO(GT1a). Together, with the fact that TR 
451 and $\mathrm{AD}$ are of the same $\mathrm{gH}$ genotype, these results suggest epistatic interplay of genetic variation of other loci 452 with that of $\mathrm{gH}$ and $\mathrm{gO}$.

In conclusion, we have shown that naturally occurring polymorphisms in the HCMV gO can have a dramatic influence on significant aspects of HCMV biology including, cell-free and cell-to-cell spread, and neutralization by anti-gH antibodies. These effects could not be explained by changes to the levels of $\mathrm{gH} / \mathrm{gL}$ complexes in the virion envelope, but rather point to changes in the mechanism(s) of $\mathrm{gH} / \mathrm{gL} / \mathrm{gO}$ in the processes of cell-free and cell-to-cell spread. The associated epistasis with the global genetic background highlights a particular challenge for intervention approaches since humans can be superinfected with several combinations of HCMV genotypes and recombination may occur frequently (1-8). Moreover, these 460 observations could help explain the incomplete protection observed for the natural antibody response against 461 HCMV. 


\section{2}

463

464

465

466

467

468

469

470

471

472

473

474

475

476

477

478

479

480

481

482

483

484

485

486

487

488

489

\section{MATERIALS AND METHODS}

Cell lines. Primary neonatal human dermal fibroblasts (nHDF; Thermo Fisher Scientific), MRC-5 fibroblasts (ATCC CCL-171; American Type Culture Collection), and HFFFtet cells (which express the tetracycline [Tet] repressor protein; provided by Richard Stanton) (51) were grown in Dulbecco's modified Eagle's medium (DMEM; Thermo Fisher Scientific) supplemented with $6 \%$ heat-inactivated fetal bovine serum (FBS; Rocky Mountain Biologicals, Inc., Missoula, MT, USA) and 6\% bovine growth serum (BGS; Rocky Mountain Biologicals, Inc., Missoula, MT, USA) and and with penicillin streptomycin, gentamycin and amphotericin B. Retinal pigment epithelial cells (ARPE19) (American Type Culture Collection, Manassas, VA, USA) were grown in a 1:1 mixture of DMEM and Ham's F-12 medium (DMEM:F-12)(Gibco) and supplemented with $10 \%$ FBS and with penicillin streptomycin, gentamycin and amphotericin B.

Human Cytomegalovirus (HCMV). All HCMV were derived from bacterial artificial chromosome (BAC) clones. The BAC clone of TR was provided by Jay Nelson (Oregon Health and Sciences University, Portland, OR, USA) (62). The BAC clone of Merlin (ME) (pAL1393), which carries tetracycline operator sequences in the transcriptional promoter of UL130 and UL131, was provided by Richard Stanton (51). All BAC clones were modified to express green fluorescent protein (GFP) by replacing the US11 ORF with the eGFP gene under the control of the murine CMV major immediate early promoter. The constitutive expression of eGFP allows the monitoring of HCMV infection early and was strain-independent. Infectious HCMV was recovered by electroporation of BAC DNA into MRC-5 fibroblasts, as described previously by Wille et al. (25) and then coculturing with nHDF or HFFFtet cells. Cell-free HCMV stocks were produced by infecting HFF or HFFFtet cells at 2 PFU per cell and harvesting culture supernatants at 8 to 10 days postinfection (when cells were still visually intact). Harvested culture supernatants were clarified by centrifugation at $1,000 \mathrm{Xg}$ for $15 \mathrm{~min}$. Stock aliquots were stored at $-80^{\circ} \mathrm{C}$. Freeze-thaw cycles were avoided. Infectious unit (IU) were determined by infecting replicate cultures of nHDF or ARPE19 with serial 10-fold dilutions and using flow cytometry to count GFP positive cells at 48 hours post infection.

Heterologous UL74(gO) recombinant HCMV. A modified, three step BAC En Passant recombineering technique was performed $(63,64)$. In the first step, the endogenous UL74 ORF from the start codon to the stop codon of both TR and ME was replaced by a selectable marker. This necessary step was added to prevent formation of chimeric UL74 gene by internal recombination of the UL74 BAC sequence and 
490 the incoming heterologous UL74 ORF. A purified PCR product containing the ampicillin resistance selectable

491 marker (AmpR) cassette from the pUC18 plasmid flanked by sequences homologous to $50 \mathrm{bp}$ upstream and downstream of the TR or ME UL74 ORF was electroporated into the bacteria, recombination was induced and the recombinant-positive bacteria were selected on medium containing ampicillin $(50 \mu \mathrm{g} / \mathrm{ml})$ and chloramphenicol $(12.5 \mu \mathrm{g} / \mathrm{ml})$. The primers used to produce the TR- and ME-specific AmpR PCR bands are For74TRamp,

CATGGGAGCTTTTTGTATCGTATTACGACATTGCTGTTTCCAGAACTTTAcgcggaacccctatttgtttattttctaaatac,

For74MEamp,

$5^{\prime}-$

GATGGGAGCTTTTTGTATCGTATTACGACATTGCTGCTTCCAGAACTTTAcgcggaacccctatttgtttattttctaaatac, and Rev74amp (used for both TR and ME PCR reactions), 5'CCAAACCACAAGGCAGACGGACGGTGCGGGGTCTCCTCCTCTGTCATGGGGttaccaatgcttaatcagtgaggcacc . The lower case nucleotides correspond to the AmpR gene from the pUC18 plasmid, the upper case nucleotides to the TR and ME BAC sequences immediately upstream and downstream of the UL74 ORF.

In the second step, the AmpR cassette in the TR and ME first-step intermediate BACs was replaced with the UL74(gO) sequence from the heterologous strain containing the En Passant cassette $(63,64)$. Briefly, E. coli cultures were prepared for recombination as described above for step 1 and electroporated with purified PCR products containing the UL74 ORF from the TR or ME strain flanked by sequence homologous to 50 bp upstream and downstream of the opposite strain. The UL74 ORF also contained an inserted En Passant cassette (an I-Scel site followed by a kanamycin resistance gene surrounded by a 50-bp duplication of the UL74 nucleotides of the insertion site). Transformed E. coli cells were induced for recombination and then selected for the swap of the UL74 En Passant sequence into the BAC by growth on medium containing kanamycin $(50 \mu \mathrm{g} / \mathrm{ml})$ and chloramphenicol $(12.5 \mu \mathrm{g} / \mathrm{ml})$. A PCR reaction analysis with primers located upstream and downstream of UL74 was used to confirm the swap of the AmpR cassette by the En Passant cassette/UL74 gene.

In the third step, several sequencing validated colonies of the second step were subjected to the last step of the En Passant recombineering, that is, an induction of both the I-Scel endonuclease and the recombinase $(63,64)$. The activity of these enzymes lead to an intramolecular recombination in the UL74 sequence around the En Passant cassette and thus the restoration of an uninterrupted, full length UL74 ORF. 
The final heterologous UL74(gO) recombinants were verified by Sanger sequencing of PCR products using primers located upstream and downstream of the UL74 gene.

Antibodies. Monoclonal antibodies (MAbs) specific to HCMV major capsid protein (MCP), pp150, and $\mathrm{gH}$ (14-4b and AP86) were provided by Bill Britt (University of Alabama, Birmingham, AL) $(35,57,65,66) .14-$ 4b and AP86 were purified by FPLC and quantified by the University of Montana Integrated Structural Biology Core Facility. Rabbit polyclonal sera against $\operatorname{HCMV~gL~was~described~previously~}(9,26)$.

Immunoblotting. HCMV cell-free virions were solubilized in $2 \%$ SDS-20 mM Tris-buffered saline (TBS) ( $\mathrm{pH} 6.8$ ). Insoluble material was cleared by centrifugation at $16,000 \times \mathrm{g}$ for $15 \mathrm{~min}$, and extracts were then boiled for $10 \mathrm{~min}$. For reducing blots, dithiothreitol (DTT) was added to extracts to a final concentration of $25 \mathrm{mM}$. After separation by SDS-PAGE, proteins were transferred onto polyvinylidene difluoride (PVDF) membranes (Whatman) in a buffer containing $10 \mathrm{mM} \mathrm{NaHCO}_{3}$ and $3 \mathrm{mM} \mathrm{Na}_{2} \mathrm{CO}_{3}$ (pH 9.9) plus $10 \%$ methanol. Transferred proteins were probed with MAbs or rabbit polyclonal antibodies, anti-rabbit or anti-mouse secondary antibodies conjugated with horseradish peroxidase (Sigma-Aldrich), and Pierce ECL-Western blotting substrate (Thermo Fisher Scientific). Chemiluminescence was detected using a Bio-Rad ChemiDoc MP imaging system. Band densities were quantified using BioRad Image Lab v 5.1.

Quantitative PCR. Viral genomes were determined as described previously (26). Briefly, cell-free HCMV stocks were treated with DNase I before extraction of viral genomic DNA (PureLink viral RNA/DNA minikit; Life Technologies/Thermo Fisher Scientific). Primers specific for sequences within UL83 were used with the MyiQ real-time PCR detection system (Bio-Rad).

Flow cytometry. Recombinant GFP-expressing HCMV-infected cells were washed twice with PBS and lifted with trypsin. Trypsin was quenched with DMEM containing 10\% FBS and cells were collected at 500 $\mathrm{g}$ for $5 \mathrm{~min}$ at RT. Cells were fixed in PBS containing $2 \%$ paraformaldehyde for $10 \mathrm{~min}$ at RT, then washed and resuspended in PBS. Samples were analyzed using an AttuneNxT flow cytometer. Cells were identified using FSC-A and SSC-A, and single cells were gated using FSC-W and FSC-H. BL-1 laser (488nm) was used to identify GFP + cells, and only cells with median GFP intensities 10-fold above background were considered positive.

Virus particle binding. nHDF or ARPE19 cells were seeded at density of 35,000 cells per $\mathrm{cm}^{2}$ on chamber slides (Nunc Lab Tek II). 2 days later, virus stocks were diluted with media to equal numbers of virus 
particles based on genome quantification by QPCR. Binding of virus particles to the cells was allowed for $20 \mathrm{~min}$ at $37^{\circ} \mathrm{C}$. Then the inoculum was removed, and the cells were washed once with medium to remove unbound virus before fixation and permeabilization with $80 \%$ acetone for $5 \mathrm{~min}$. Bound virus particles were stained with an antibody against the capsid-associated tegument protein pp150 (65) which allowed to detect enveloped particles attached to the plasma membrane as well as internalized particles. For visualization, a goat antimouse Alexa Fluor 488 (Invitrogen) secondary antibody was used. Unbound secondary antibody was washed off before the chambers were removed and the cells were mounted with medium containing DAPI (Fluoroshield) and sealed with a cover slide for later immunofluorescence analysis. Images were taken with a Leica DM5500 at 630 -fold magnification. For each sample 10 images with 4 to 6 cells per image were taken and the number of cell nuclei as well as the number of virus particles was determined using Image $J$ Fiji software ( $v$ 1.0). Three independent virus stocks were tested in 3 independent experiments.

Antibody neutralization assays. Equal numbers of nHDF-derived cell-free parental viruses and heterologous gO recombinants were incubated with multiple concentrations of anti-gH mAb 14-4b or AP86 for $1 \mathrm{hr}$ at $\mathrm{RT}$ then plated on $\mathrm{nHDF}$ or ARPE19 for $4 \mathrm{hrs}$ at $37^{\circ} \mathrm{C}$. Cells were then cultured in the appropriate growth medium supplemented with 2\% FBS. After 2 days, cells were detected from the dish and fixed for flow cytometry analyses. Each antibody concentration was performed in triplicate and 3 independent experiments were conducted.

\section{ACKNOWLEDGMENTS}

We are grateful to Bill Britt, David Johnson, Jay Nelson, and Richard Stanton for generously supplying HCMV BAC clones, antibodies, and cell lines as indicated in the Material and Methods, and members of the Ryckman laboratory for support, and insightful discussions. We also thank Ekaterina Voronina and Mary Ellenbecker of University of Montana for assistance with immunofluorescent microscopy, the staff of the University of Montana Center for Biomolecular Structure and Dynamics Integrated Structural Biology Core Facility for help purifying monoclonal antibodies, and the staff of the University of Montana Flow Cytometry Core of the Center for Environmental Heath Sciences for assistance with flow cytometry.

This work was supported by grant from the National Institutes of Health to B.J.R (R01Al097274), a fellowship from the German Research Foundation (DFG) to C.S. (STE 2835/1-1), a fellowship from American 
Heart Association to E.P.S (17POST33350043) and a National Institutes of Health CoBRE award to Center for

Biomolecular Structure and Dynamics at University of Montana (PG20GM103546).

Experiments were designed by B.J.R., L.Z.D, C.S., and E.P.S, and performed by L.Z. and C.S. Critical

reagents were developed by L.Z.D., J.M.L. and Q.Y. Data were analyzed, and manuscript was prepared by

B.J.R., L.Z.D., C.S., Q.Y., E.P.S., and J.M.L.

\section{REFERENCES}

1. Cudini J, Roy S, Houldcroft CJ, Bryant JM, Depledge DP, Tutill H, Veys P, Williams R, Worth AJJ, Tamuri AU, Goldstein RA, Breuer J. 2019. Human cytomegalovirus haplotype reconstruction reveals high diversity due to superinfection and evidence of within-host recombination. Proceedings of the National Academy of Sciences 116:5693-5698.

2. Hage E, Wilkie GS, Linnenweber-Held S, Dhingra A, Suárez NM, Schmidt JJ, Kay-Fedorov PC, Mischak-Weissinger E, Heim A, Schwarz A, Schulz TF, Davison AJ, Ganzenmueller T. 2017. Characterization of Human Cytomegalovirus Genome Diversity in Immunocompromised Hosts by WholeGenome Sequencing Directly From Clinical Specimens. The Journal of Infectious Diseases 215:16731683.

3. Lassalle F, Depledge DP, Reeves MB, Brown AC, Christiansen MT, Tutill HJ, Williams RJ, EinerJensen K, Holdstock J, Atkinson C, Brown JR, van Loenen FB, Clark DA, Griffiths PD, Verjans GMGM, Schutten M, Milne RSB, Balloux F, Breuer J. 2016. Islands of linkage in an ocean of pervasive recombination reveals two-speed evolution of human cytomegalovirus genomes. Virus Evol 2:vew017.

4. Renzette N, Bhattacharjee B, Jensen JD, Gibson L, Kowalik TF. 2011. Extensive genome-wide variability of human cytomegalovirus in congenitally infected infants. PLoS Pathog 7:e1001344.

5. Renzette N, Gibson L, Bhattacharjee B, Fisher D, Schleiss MR, Jensen JD, Kowalik TF. 2013. Rapid Intrahost Evolution of Human Cytomegalovirus Is Shaped by Demography and Positive Selection. PLoS Genet 9:e1003735.

6. Sijmons S, Thys K, Mbong Ngwese M, Van Damme E, Dvorak J, Van Loock M, Li G, Tachezy R, Busson L, Aerssens J, Van Ranst M, Maes P. 2015. High-throughput analysis of human cytomegalovirus genome diversity highlights the widespread occurrence of gene-disrupting mutations and pervasive recombination. J Virol

7. Suarez N, Musonda KG, Escriva E, Njenga M, Agbueze A, Camiolo S, Davison AJ, Gompels UA. 2018. Multiple-Strain Infections of Human Cytomegalovirus with High Genomic Diversity are Common In Breast Milk from HIV-Positive Women in Zambia.

8. Suárez NM, Wilkie GS, Hage E, Camiolo S, Holton M, Hughes J, Maabar MD, Sreenu VB, Dhingra A, Gompels UA, Wilkinson GWG, Baldanti F, Furione M, Lilleri D, Arossa A, Ganzenmueller T, Gerna G, Hubáček P, Schulz TF, Wolf D, Zavattoni M, Davison AJ. 2019. Human Cytomegalovirus Genomes Sequenced Directly from Clinical Material: Variation, Multiple-Strain Infection, Recombination and Gene Loss. J Infect Dis

9. Zhou M, Yu Q, Wechsler A, Ryckman BJ. 2013. Comparative analysis of $\mathrm{gO}$ isoforms reveals that strains of human cytomegalovirus differ in the ratio of $\mathrm{gH} / \mathrm{gL} / \mathrm{gO}$ and $\mathrm{gH} / \mathrm{gL} / \mathrm{UL} 128-131$ in the virion envelope. J Virol 87:9680-9690.

10. Rasmussen L, Geissler A, Cowan C, Chase A, Winters M. 2002. The genes encoding the gCIII complex of human cytomegalovirus exist in highly diverse combinations in clinical isolates. $J$ Virol 76:10841-10848.

11. Stanton R, Westmoreland D, Fox JD, Davison AJ, Wilkinson GW. 2005. Stability of human cytomegalovirus genotypes in persistently infected renal transplant recipients. J Med Virol 75:42-46.

12. Mattick C, Dewin D, Polley S, Sevilla-Reyes E, Pignatelli S, Rawlinson W, Wilkinson G, Dal Monte P, Gompels UA. 2004. Linkage of human cytomegalovirus glycoprotein gO variant groups identified from worldwide clinical isolates with $\mathrm{gN}$ genotypes, implications for disease associations and evidence for $\mathrm{N}$ terminal sites of positive selection. Virology 318:582-597.

13. Gorzer I, Guelly C, Trajanoski S, Puchhammer-StockI E. 2010. Deep sequencing reveals highly complex dynamics of human cytomegalovirus genotypes in transplant patients over time. J Virol 
84:7195-7203.

14. Cooper RS, Heldwein EE. 2015. Herpesvirus gB: A Finely Tuned Fusion Machine. Viruses 7:65526569.

15. Heldwein EE. 2016. gH/gL supercomplexes at early stages of herpesvirus entry. Curr Opin Virol 18:1-8.

16. Connolly SA, Jackson JO, Jardetzky TS, Longnecker R. 2011. Fusing structure and function: a structural view of the herpesvirus entry machinery. Nat Rev Microbiol 9:369-381.

17. Wang D, Shenk T. 2005. Human cytomegalovirus virion protein complex required for epithelial and endothelial cell tropism. Proc Natl Acad Sci U S A 102:18153-18158.

18. Li L, Nelson JA, Britt WJ. 1997. Glycoprotein H-related complexes of human cytomegalovirus: identification of a third protein in the gClll complex. J Virol 71:3090-3097.

19. Huber MT, Compton T. 1997. Characterization of a novel third member of the human cytomegalovirus glycoprotein H-glycoprotein L complex. J Virol 71:5391-5398.

20. Vanarsdall AL, Howard PW, Wisner TW, Johnson DC. 2016. Human Cytomegalovirus $\mathrm{gH} / \mathrm{gL}$ Forms a Stable Complex with the Fusion Protein gB in Virions. PLoS Pathog 12:e1005564.

21. Hahn G, Revello MG, Patrone M, Percivalle E, Campanini G, Sarasini A, Wagner M, Gallina A, Milanesi G, Koszinowski U, Baldanti F, Gerna G. 2004. Human cytomegalovirus UL131-128 genes are indispensable for virus growth in endothelial cells and virus transfer to leukocytes. J Virol 78:1002310033.

22. Jiang XJ, Adler B, Sampaio KL, Digel M, Jahn G, Ettischer N, Stierhof YD, Scrivano L, Koszinowski U, Mach M, Sinzger C. 2008. UL74 of human cytomegalovirus contributes to virus release by promoting secondary envelopment of virions. J Virol 82:2802-2812.

23. Ryckman BJ, Jarvis MA, Drummond DD, Nelson JA, Johnson DC. 2006. Human cytomegalovirus entry into epithelial and endothelial cells depends on genes UL128 to UL150 and occurs by endocytosis and low-pH fusion. J Virol 80:710-722.

24. Wang D, Shenk T. 2005. Human cytomegalovirus UL131 open reading frame is required for epithelial cell tropism. J Virol 79:10330-10338.

25. Wille PT, Knoche AJ, Nelson JA, Jarvis MA, Johnson DC. 2010. A human cytomegalovirus gO-null mutant fails to incorporate $\mathrm{gH} / \mathrm{gL}$ into the virion envelope and is unable to enter fibroblasts and epithelial and endothelial cells. J Virol 84:2585-2596.

26. Zhou M, Lanchy JM, Ryckman BJ. 2015. Human cytomegalovirus $\mathrm{gH} / \mathrm{gL} / \mathrm{gO}$ promotes the fusion step of entry into all cell types whereas $\mathrm{gH} / \mathrm{gL} / \mathrm{UL} 128-131$ broadens virus tropism through a distinct mechanism. J Virol

27. Laib Sampaio K, Stegmann C, Brizic I, Adler B, Stanton RJ, Sinzger C. 2016. The contribution of pUL74 to growth of human cytomegalovirus is masked in the presence of RL13 and UL128 expression. $J$ Gen Virol 97:1917-1927.

28. Wu K, Oberstein A, Wang W, Shenk T. 2018. Role of PDGF receptor- $\alpha$ during human cytomegalovirus entry into fibroblasts. Proc Natl Acad Sci U S A 115:E9889-E9898.

29. E X, Meraner P, Lu P, Perreira JM, Aker AM, McDougall WM, Zhuge R, Chan GC, Gerstein RM, Caposio P, Yurochko AD, Brass AL, Kowalik TF. 2019. OR14l1 is a receptor for the human cytomegalovirus pentameric complex and defines viral epithelial cell tropism. Proc Natl Acad Sci U S A 116:7043-7052.

30. Kabanova A, Marcandalli J, Zhou T, Bianchi S, Baxa U, Tsybovsky Y, Lilleri D, Silacci-Fregni C, Foglierini M, Fernandez-Rodriguez BM, Druz A, Zhang B, Geiger R, Pagani M, Sallusto F, Kwong PD, Corti D, Lanzavecchia A, Perez L. 2016. Platelet-derived growth factor-alpha receptor is the cellular receptor for human cytomegalovirus gHgLgO trimer. Nat Microbiol 2016

31. Martinez-Martin N, Marcandalli J, Huang CS, Arthur CP, Perotti M, Foglierini M, Ho H, Dosey AM, Shriver S, Payandeh J, Leitner A, Lanzavecchia A, Perez L, Ciferri C. 2018. An Unbiased Screen for Human Cytomegalovirus Identifies Neuropilin-2 as a Central Viral Receptor. Cell 174:1158-1171.e19.

32. Wu Y, Prager A, Boos S, Resch M, Brizic I, Mach M, Wildner S, Scrivano L, Adler B. 2017. Human cytomegalovirus glycoprotein complex $\mathrm{gH} / \mathrm{gL} / \mathrm{gO}$ uses PDGFR- $\alpha$ as a key for entry. PLoS Pathog 13:e1006281.

33. Stegmann C, Hochdorfer D, Lieber D, Subramanian N, Stöhr D, Laib Sampaio K, Sinzger C. 2017. A derivative of platelet-derived growth factor receptor alpha binds to the trimer of human cytomegalovirus and inhibits entry into fibroblasts and endothelial cells. PLoS Pathog 13:e1006273.

34. Vanarsdall AL, Ryckman BJ, Chase MC, Johnson DC. 2008. Human cytomegalovirus glycoproteins $\mathrm{gB}$ and $\mathrm{gH} / \mathrm{gL}$ mediate epithelial cell-cell fusion when expressed either in cis or in trans. J Virol 
82:11837-11850.

35. Bogner E, Reschke M, Reis B, Reis E, Britt W, Radsak K. 1992. Recognition of compartmentalized intracellular analogs of glycoprotein $\mathrm{H}$ of human cytomegalovirus. Arch Virol 126:67-80.

36. Chiuppesi F, Wussow F, Johnson E, Bian C, Zhuo M, Rajakumar A, Barry PA, Britt WJ, Chakraborty R, Diamond DJ. 2015. Vaccine-Derived Neutralizing Antibodies to the Human Cytomegalovirus $\mathrm{gH} / \mathrm{gL}$ Pentamer Potently Block Primary Cytotrophoblast Infection. J Virol

37. Fouts AE, Chan P, Stephan JP, Vandlen R, Feierbach B. 2012. Antibodies against the $\mathrm{gH} / \mathrm{gL} / \mathrm{UL} 128 / \mathrm{UL} 130 / \mathrm{UL} 131$ complex comprise the majority of the anti-cytomegalovirus (anti-CMV) neutralizing antibody response in CMV hyperimmune globulin. J Virol 86:7444-7447.

38. Fouts AE, Comps-Agrar L, Stengel KF, Ellerman D, Schoeffler AJ, Warming S, Eaton DL, Feierbach B. 2014. Mechanism for neutralizing activity by the anti-CMV gH/gL monoclonal antibody MSL-109. Proc Natl Acad Sci U S A 111:8209-8214.

39. Gerna G, Percivalle E, Perez L, Lanzavecchia A, Lilleri D. 2016. Monoclonal Antibodies to Different Components of the Human Cytomegalovirus (HCMV) Pentamer $\mathrm{gH} / \mathrm{gL} / \mathrm{pUL} 128 \mathrm{~L}$ and Trimer $\mathrm{gH} / \mathrm{gL} / \mathrm{gO}$ as well as Antibodies Elicited during Primary HCMV Infection Prevent Epithelial Cell Syncytium Formation. J Virol 90:6216-6223.

40. Kabanova A, Perez L, Lilleri D, Marcandalli J, Agatic G, Becattini S, Preite S, Fuschillo D, Percivalle E, Sallusto F, Gerna G, Corti D, Lanzavecchia A. 2014. Antibody-driven design of a human cytomegalovirus gHgLpUL128L subunit vaccine that selectively elicits potent neutralizing antibodies. Proc Natl Acad Sci U S A 111:17965-17970.

41. Nokta M, Tolpin MD, Nadler PI, Pollard RB. 1994. Human monoclonal anti-cytomegalovirus (CMV) antibody (MSL 109): enhancement of in vitro foscarnet- and ganciclovir-induced inhibition of CMV replication. Antiviral Res 24:17-26.

42. Vanarsdall AL, Chin AL, Liu J, Jardetzky TS, Mudd JO, Orloff SL, Streblow D, Mussi-Pinhata MM, Yamamoto AY, Duarte G, Britt WJ, Johnson DC. 2019. HCMV trimer- and pentamer-specific antibodies synergize for virus neutralization but do not correlate with congenital transmission. Proc Natl Acad Sci U S A 116:3728-3733.

43. Wussow F, Chiuppesi F, Martinez J, Campo J, Johnson E, Flechsig C, Newell M, Tran E, Ortiz J, La Rosa C, Herrmann A, Longmate J, Chakraborty R, Barry PA, Diamond DJ. 2014. Human cytomegalovirus vaccine based on the envelope $\mathrm{gH} / \mathrm{gL}$ pentamer complex. PLoS Pathog 10:e1004524.

44. Wei X, Decker JM, Wang S, Hui H, Kappes JC, Wu X, Salazar-Gonzalez JF, Salazar MG, Kilby JM, Saag MS, Komarova NL, Nowak MA, Hahn BH, Kwong PD, Shaw GM. 2003. Antibody neutralization and escape by HIV-1. Nature 422:307-312.

45. Kropff B, Burkhardt C, Schott J, Nentwich J, Fisch T, Britt W, Mach M. 2012. Glycoprotein N of human cytomegalovirus protects the virus from neutralizing antibodies. PLoS Pathog 8:e1002999.

46. Jiang XJ, Sampaio KL, Ettischer N, Stierhof YD, Jahn G, Kropff B, Mach M, Sinzger C. 2011. UL74 of human cytomegalovirus reduces the inhibitory effect of $\mathrm{gH}$-specific and gB-specific antibodies. Arch Virol

47. Cui X, Freed DC, Wang D, Qiu P, Li F, Fu TM, Kauvar LM, McVoy MA. 2017. Impact of Antibodies and Strain Polymorphisms on Cytomegalovirus Entry and Spread in Fibroblasts and Epithelial Cells. J Virol 91

48. Zhang L, Zhou M, Stanton R, Kamil J, Ryckman BJ. 2018. Expression levels of glycoprotein O (gO) vary between strains of human cytomegalovirus, influencing the assembly of $\mathrm{gH} / \mathrm{gL}$ complexes and virion infectivity. J Virol

49. Kalser J, Adler B, Mach M, Kropff B, Puchhammer-Stöckl E, Görzer I. 2017. Differences in Growth Properties among Two Human Cytomegalovirus Glycoprotein O Genotypes. Front Microbiol 8:1609.

50. Murrell I, Bedford C, Ladell K, Miners KL, Price DA, Tomasec P, Wilkinson GWG, Stanton RJ. 2017. The pentameric complex drives immunologically covert cell-cell transmission of wild-type human cytomegalovirus. Proc Natl Acad Sci U S A

51. Stanton RJ, Baluchova K, Dargan DJ, Cunningham C, Sheehy O, Seirafian S, McSharry BP, Neale ML, Davies JA, Tomasec P, Davison AJ, Wilkinson GW. 2010. Reconstruction of the complete human cytomegalovirus genome in a BAC reveals RL13 to be a potent inhibitor of replication. J Clin Invest 120:3191-3208.

52. Murrell I, Wilkie GS, Davison AJ, Statkute E, Fielding CA, Tomasec P, Wilkinson GW, Stanton RJ. 2016. Genetic Stability of Bacterial Artificial Chromosome-Derived Human Cytomegalovirus during Culture In Vitro. J Virol 90:3929-3943.

53. Vanarsdall AL, Wisner TW, Lei H, Kazlauskas A, Johnson DC. 2012. PDGF receptor-alpha does not 
promote HCMV entry into epithelial and endothelial cells but increased quantities stimulate entry by an abnormal pathway. PLoS Pathog 8:e1002905.

54. Liu J, Jardetzky TS, Chin AL, Johnson DC, Vanarsdall AL. 2018. The human cytomegalovirus trimer and pentamer promote sequential steps in entry into epithelial and endothelial cells at cell surfaces and endosomes. Journal of Virology JVI.01336-18.

55. Murrell I, Tomasec P, Wilkie GS, Dargan DJ, Davison AJ, Stanton RJ. 2013. Impact of sequence variation in the UL128 locus on production of human cytomegalovirus in fibroblast and epithelial cells. J Virol 87:10489-10500.

56. Schultz EP, Lanchy JM, Ellerbeck EE, Ryckman BJ. 2015. Scanning Mutagenesis of Human Cytomegalovirus Glycoprotein gH/gL. J Virol 90:2294-2305.

57. Urban M, Britt W, Mach M. 1992. The dominant linear neutralizing antibody-binding site of glycoprotein gp86 of human cytomegalovirus is strain specific. J Virol 66:1303-1311.

58. Ourahmane A, Cui X, He L, Catron M, Dittmer DP, Al Qaffasaa A, Schleiss MR, Hertel L, McVoy MA. 2019. Inclusion of Antibodies to Cell Culture Media Preserves the Integrity of Genes Encoding RL13 and the Pentameric Complex Components During Fibroblast Passage of Human Cytomegalovirus. Viruses 11

59. Scrivano L, Sinzger C, Nitschko H, Koszinowski UH, Adler B. 2011. HCMV spread and cell tropism are determined by distinct virus populations. PLoS Pathog 7:e1001256.

60. Stegmann C, Rothemund F, Laib Sampaio K, Adler B, Sinzger C. 2019. The N Terminus of Human Cytomegalovirus Glycoprotein O Is Important for Binding to the Cellular Receptor PDGFRa. Journal of Virology 93

61. Chou S. 1992. Molecular epidemiology of envelope glycoprotein H of human cytomegalovirus. J Infect Dis 166:604-607.

62. Murphy E, Yu D, Grimwood J, Schmutz J, Dickson M, Jarvis MA, Hahn G, Nelson JA, Myers RM, Shenk TE. 2003. Coding potential of laboratory and clinical strains of human cytomegalovirus. Proc Natl Acad Sci U S A 100:14976-14981.

63. Tischer BK, von Einem J, Kaufer B, Osterrieder N. 2006. Two-step red-mediated recombination for versatile high-efficiency markerless DNA manipulation in Escherichia coli. Biotechniques 40:191-197.

64. Tischer BK, Smith GA, Osterrieder N. 2010. En passant mutagenesis: a two step markerless red recombination system. Methods Mol Biol 634:421-430.

65. Sanchez V, Greis KD, Sztul E, Britt WJ. 2000. Accumulation of virion tegument and envelope proteins in a stable cytoplasmic compartment during human cytomegalovirus replication: characterization of a potential site of virus assembly. J Virol 74:975-986.

66. Chee M, Rudolph SA, Plachter B, Barrell B, Jahn G. 1989. Identification of the major capsid protein gene of human cytomegalovirus. J Virol 63:1345-1353. 


\section{FIGURE LEGENDS}

Figure 1. Immunoblot analysis of $\mathrm{gH} / \mathrm{gL}$ complexes in parental and heterologous gO recombinant HCMV. Equal number of cell-free virions (as determined by qPCR) of HCMV TR (A), ME (B), or MT (C) or the corresponding heterologous gO recombinants were separated by reducing (upper two panels) or non-reducing (bottom panel) SDS-PAGE, and analyzed by immunoblot with antibodies specific for major capsid protein (MCP) or gL. Blots shown are representative of three independent experiments. Molecular mass markers $(\mathrm{kDa})$ indicated on each panel.

Figure 2. Relative fibroblast and epithelial cell tropism of parental and heterologous gO recombinant HCMV. Cell-free stocks of HCMV TR (A), ME (B), or MT (C) or the corresponding heterologous gO recombinants were serially diluted, and side-by-side cultures of nHDF fibroblasts and ARPE19 epithelial cells were inoculated with equal volumes of the dilutions. The number of infected cells was determined by flow cytometry for GFP at 2 days post infection. Ratios greater than or equal to 1 of the number of each cell type infected (fib/epi or epi/fib) are plotted for each of three independent sets of virus stocks (black, open and striped bars).

Figure 3. Specific infectivity of parental and heterologous gO recombinant HCMV. Extracellular HCMV stocks of HCMV TR (A), ME (B), or MT (C) or the corresponding heterologous gO recombinants were quantified by qPCR for viral genomes, and infectious units (IU) were determined by flow cytometry quantification of GFP-expressing nHDF fibroblasts or ARPE-19 epithelial cells, 2 days post infection. Average genomes/IU of 3 independent set of virus stock are plotted, with error bars representing standard deviations. Undetectable levels of infectivity indicated by ND (not determined). Asterisks $\left(^{*}\right)$ denote $p$-values $\leq 0.05$; oneway ANOVA with Dunnett's multiple comparisons test comparing each recombinant to the parental in three independent experiments.

Figure 4. Binding of parental and heterologous gO recombinant HCMV to fibroblasts. Extracellular HCMV TR, ME, MT or the corresponding heterologous gO recombinants were applied to $\mathrm{nHDF}$ for $20 \mathrm{~min}$. Multiplicities (genomes/cell) were: TR-background viruses $\left(1 \times 10^{4}\right)$, ME-background viruses $\left(5 \times 10^{4}\right)$, MT- 
background viruses $\left(1 \times 10^{4}\right)$. After washing away unbound virus, cultures were fixed and permeabilized with acetone and cell-associated virus particles were detected by immunofluorescence using antibodies specific for the capsid-associated tegument protein, pp150. Cells were visualized by staining nuclei with DAPI.

Representative fields of parental TR, ME, MT and heterologous gO recombinants that consistently reduced binding in 3 independent experiments (Table 2). (B) Mean particles per cell for representative experiments. Error bars represent the standard deviation. Asterisks $\left(^{*}\right)$ denote p-values $\leq 0.05$; one-way ANOVA with Dunnett's multiple comparisons test comparing each recombinant to the parental.

Figure 5. Spread of parental and heterologous gO recombinant HCMV in fibroblast cultures. Confluent monolayers of nHDF or HFFFTet (for "MT") were infected with 0.003/cell of HCMV TR (A, B), ME (A, C), MT (A, D) or the corresponding heterologous gO recombinants. At 3 and 12 days post infection cultures were analyzed by fluorescence microscopy (A) or by flow cytometry to quantitate the total number of infected $(G F P+)$ cells (B-D). Plotted are the average number of infected cells at day 12 per infected cell at day 3 in 3 independent experiments. Error bars represent standard deviations. Asterisks $\left({ }^{*}\right)$ denote $p$-values $\leq 0.05$; one-way ANOVA with Dunnett's multiple comparisons test comparing each recombinant to the parental.

Figure 6. Release of extracellular progeny by parental and heterologous gO recombinant HCMV in fibroblast cultures. Cultures of nHDF or HFFFTet (for "MT") were infected with 1 IU/cell of HCMV TR (A), ME (B), MT (C) or the corresponding heterologous gO recombinants for 8 days. The number of infected cells was determined by flow cytometry and progeny virus in culture supernatants was quantified by GPCR for viral genomes. The average number of extracellular virions per $\mathrm{mL}$ in each of 3 independent experiments is plotted. Error bars represent standard deviations. Asterisks $\left(^{*}\right)$ denote $p$-values $\leq 0.05$; one-way ANOVA with Dunnett's multiple comparisons test comparing each recombinant to the parental.

Figure 7. Spread of parental and heterologous go recombinant HCMV in epithelial cell cultures. Confluent monolayers of ARPE19 cells were infected with $0.003 \mathrm{IU} /$ cell of HCMV TR (A, B), ME (A, C), or the corresponding heterologous gO recombinants. At 3 and 12 days post infection cultures were analyzed by fluorescence microscopy (A) or by flow cytometry to quantitate the total number of infected (GFP+) cells (B-D). 
Plotted are the average number of infected cells at day 12 per infected cell at day 3 in 3 independent experiments. Error bars represent standard deviations Asterisks $\left({ }^{*}\right)$ denote $p$-values $\leq 0.05$; one-way ANOVA with Dunnett's multiple comparisons test comparing each recombinant to the parental.

Figure 8. Release of extracellular progeny by parental and heterologous gO recombinant HCMV ME in epithelial cell cultures. Cultures of ARPE19 epithelial cells were infected with HFFF-tet-derived MT or corresponding heterologous $\mathrm{gO}$ recombinants at the highest multiplicities possible given the specific infectivity of stocks reported in Fig 3 (approximately $0.0005 \mathrm{IU} /$ cell). (Note: since APRE19 cells do not express TetR, after the initial infection, MT replicates as ME). Cultures were then propagated by trypsinization and reseeding of intact cells until the number of infected cells approached $90-100 \%$ by microscopy inspection for GFP+ cells. After 8 more days, culture supernatants were then analyzed by quantified by qPCR for viral genomes. The average number of extracellular virions per $\mathrm{mL}$ in each of 3 independent experiments is plotted. Error bars represent standard deviations. Asterisks $\left(^{*}\right)$ denote $p$-values $\leq 0.05$; one-way ANOVA with Dunnett's multiple comparisons test comparing each recombinant to the parental.

Figure 9. Neutralization of parental HCMV TR and heterologous gO recombinant by anti-gH antibodies. Genome equivalents of extracellular HCMV TR or the corresponding heterologous gO recombinants were incubated with $0.025-250 \mu \mathrm{g} / \mathrm{mL}$ of anti-gH mAb $14-4 \mathrm{~b}$, or $0.01-100 \mu \mathrm{g} / \mathrm{mL}$ of anti-gH mAb AP86 and then plated on cultures of nHDF fibroblasts (A and B) or ARPE19 epithelial cells ( $C$ and D). At 2 days post infection the number of infected (GFP+) cells was determined by flow cytometry and plotted as the percent of the no antibody control. (Left panels) Full titration curves shown are representative of three independent experiments, each performed in triplicate. (Right panels) Average percent of cells infected at the highest antibody concentrations in 3 independent experiments. Error bars represent standard deviations. Asterisks $\left({ }^{*}\right)$ denote $p$ values $\leq 0.05$; one-way ANOVA with Dunnett's multiple comparisons test comparing each recombinant to the parental.

Figure 10. Neutralization of parental HCMV MT and heterologous gO recombinant by anti-gH antibodies. Genome equivalents of extracellular extracellular HCMV MT or the corresponding heterologous 
gO recombinants were incubated with $0.025-250 \mu \mathrm{g} / \mathrm{mL}$ of anti-gH mAb $14-4 \mathrm{~b}$ and then plated on cultures of nHDF fibroblasts (A) or ARPE19 epithelial cells (B). At 2 days post infection the number of infected $(G F P+)$ cells was determined by flow cytometry and plotted as the percent of the no antibody control. (Left panels) Full titration curves shown are representative of three independent experiments, each performed in triplicate. (Right panels) Average percent of cells infected at the highest antibody concentrations in 3 independent experiments. Error bars represent standard deviations. Asterisks $\left({ }^{*}\right)$ denote p-values $\leq 0.05$; one-way ANOVA with Dunnett's multiple comparisons test comparing each recombinant to the parental.

Figure 11. Association of $\mathrm{gH}$ and $\mathrm{gO}$ genotypes in 236 complete HCMV genome sequences in the NCBI database. Complete HCMV genome sequences were retrieved from the NCBI nucleotide database using the keywords filter <human herpesvirus type 5 complete genome>. The resulting set of 350 sequences was curated to remove duplicates or genomes missing any of the $U L 74(\mathrm{gO})$ and $U L 75(\mathrm{gH})$ open reading frames, generating a working set of 236 complete HCMV genomes, which were analyzed using MAFFT FFT-NS-i (v7.429) phylogeny software. $U L 74(g O)$ and $U L 75(g H)$ sequences were assigned to their respective genotype groups as defined previously; UL75(gH) genotypes 1 and $2(57,61)$; UL74(gO) genotypes 1a, 1b, 1c, 2a, 2b,

3,4 and $5(10,12)$. Shown is a phylogenetic tree of the $8 \mathrm{gO}$ genotypes with the frequency of pairing with either $\mathrm{gH} 1$ or $\mathrm{gH} 2$. Asterisks $\left(^{*}\right)$ indicate $\mathrm{gO}$ genotypes that were not analyzed in the experiments described herein. 
Table 1. Immunoblot band density analyses of parental and heterologous go recombinants

\begin{tabular}{|c|c|c|c|c|c|c|c|c|}
\hline $\begin{array}{c}\text { Genotype } \\
\text { Background }\end{array}$ & \multicolumn{8}{|c|}{ Virion Protein(s) Analyzed } \\
\hline TR & \multicolumn{2}{|c|}{ MCP } & \multicolumn{2}{|c|}{$g \mathrm{~L}$} & \multicolumn{2}{|c|}{$\mathrm{gH} / \mathrm{gL} / \mathrm{gO}$} & \multicolumn{2}{|c|}{$\mathrm{gH} / \mathrm{gL} / \mathrm{UL} 128$} \\
\hline gO genotype & Fold & ANOVA $^{c}$ & Fold & p-value & Fold & ANOVA & Fold & ANOVA \\
\hline $\mathrm{TR}(\mathrm{GT1b})$ & - & - & - & - & - & - & - & - \\
\hline MEgO(GT5) & 1.1 & ns & 0.6 & ns & 1.4 & ns & 2.0 & ns \\
\hline $\mathrm{PHgO}(\mathrm{GT} 2 \mathrm{a})$ & 1.1 & ns & 0.9 & ns & 1.8 & ns & 2.3 & * \\
\hline TBgO (GT1c) & 1.2 & ns & 0.8 & ns & 0.9 & ns & 0.9 & ns \\
\hline $\mathrm{ADgO}(\mathrm{GT} 1 \mathrm{a})$ & 1.1 & ns & 0.9 & ns & 0.9 & ns & 1.0 & ns \\
\hline TNgO (GT4) & 1.1 & ns & 2.0 & ns & 2.7 & ns & 2.1 & ns \\
\hline ME & \multicolumn{2}{|c|}{ MCP } & \multicolumn{2}{|c|}{$g \mathrm{~L}$} & \multicolumn{2}{|c|}{$\mathrm{gH} / \mathrm{gL} / \mathrm{gO}$} & \multicolumn{2}{|c|}{$\mathrm{gH} / \mathrm{gL} / \mathrm{UL} 128$} \\
\hline gO genotype & Fold & ANOVA & Fold & ANOVA & Fold & ANOVA & Fold & ANOVA \\
\hline $\mathrm{MEgO}(\mathrm{GT} 5)$ & (n) & 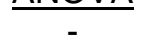 & - & - & - & - & - & - \\
\hline TR(GT1b) & 0.9 & ns & 0.8 & ns & 0.9 & ns & 1.1 & ns \\
\hline $\mathrm{PHgO}(\mathrm{GT} 2 \mathrm{a})$ & 1.1 & ns & 1.1 & ns & 1.4 & ns & 1.4 & ns \\
\hline TBgO (GT1c) & 1.3 & ns & 1.2 & ns & 1.0 & ns & 1.4 & ns \\
\hline $\mathrm{ADgO}$ (GT1a) & 1.0 & ns & 0.7 & ns & 0.9 & ns & 1.1 & ns \\
\hline $\mathrm{TNgO}$ (GT4) & 1.1 & ns & 0.8 & ns & 0.9 & ns & 1.4 & ns \\
\hline MT & \multicolumn{2}{|c|}{ MCP } & \multicolumn{2}{|c|}{$g \mathrm{~L}$} & \multicolumn{2}{|c|}{$\mathrm{gH} / \mathrm{gL} / \mathrm{gO}$} & \multicolumn{2}{|c|}{$\mathrm{gH} / \mathrm{gL} / \mathrm{UL} 128$} \\
\hline$\frac{\text { gO genotype }}{\mathrm{MFgO}(\mathrm{GT})^{2}}$ & Fold & $\frac{\text { ANOVA }}{-}$ & Fold & ANOVA & Fold & ANOVA & Fold & ANOVA \\
\hline TR(GT1b) & 1.1 & ns & 1.2 & ns & 0.7 & ns & $\overline{0.9}$ & - \\
\hline $\mathrm{PHgO}(\mathrm{GT} 2 \mathrm{a})$ & 1.1 & ns & 1.6 & ns & 1.4 & ns & 1.1 & ns \\
\hline TBgO (GT1c) & 1.1 & ns & 1.3 & ns & 1.1 & ns & 1.6 & ns \\
\hline ADgO (GT1a) & 0.8 & ns & 0.5 & ns & 0.6 & ns & 1.7 & ns \\
\hline TNgO (GT4) & 0.9 & ns & 0.7 & ns & 1.4 & ns & 1.8 & ns \\
\hline
\end{tabular}

a. Three independent stocks of cell-free virions collected from infected nHDF (for TR and ME) or HFFF-tet (for MT) culture supernatants and analyzed by immunoblot as described for Figure 1.

b. Mean fold difference of chemiluminescent band densities obtained for each recombinant compared to the parental TR in three independent experiments.

c. One-way ANOVA with Dunnett's multiple comparisons test comparing each recombinant to the parental in three independent experiments. $\left(^{*}\right) p \leq 0.05$, (ns) not significant. 
bioRxiv preprint doi: https://doi.org/10.1101/867234; this version posted January 20,2020 . The copyright holder for this preprint (which was not certified by peer review) is the author/funder, who has granted bioRxiv a license to display the preprint in perpetuity. It is made available under aCC-BY-ND 4.0 International license.

Table 2. Binding of parental and heterologous gO recombinant HCMV to fibroblasts.

\begin{tabular}{|c|c|c|c|c|c|c|c|c|c|}
\hline $\begin{array}{c}\text { Genotype } \\
\text { Background }\end{array}$ & \multicolumn{3}{|c|}{$\frac{\text { Experiment } 1}{\left.\text { (input }^{\mathrm{a}}\right)}$} & \multicolumn{3}{|c|}{$\frac{\text { Experiment } 2}{\text { (input) }}$} & \multicolumn{3}{|c|}{$\frac{\text { Experiment } 3}{\text { (input) }}$} \\
\hline TR & \multicolumn{3}{|c|}{$\left(6.2 \times 10^{7}\right)$} & \multicolumn{3}{|c|}{$\left(7.5 \times 10^{7}\right)$} & \multicolumn{3}{|c|}{$\left(1.0 \times 10^{8}\right)$} \\
\hline gO genotype & Mean $^{b}$ & Fold $^{c}$ & ANOVA $^{d}$ & Mean & Fold & ANOVA & Mean & Fold & ANOVA \\
\hline TR(GT1b) & 17.8 & - & - & 31.2 & - & - & 30.4 & - & - \\
\hline MEgO(GT5) & 21.2 & - & ns & 44.7 & 1.4 & * & 37.9 & - & ns \\
\hline PHgO(GT2a) & 24.3 & - & ns & 12.7 & 0.41 & * & 35.3 & - & ns \\
\hline TBgO (GT1c) & 18.8 & - & ns & 30.5 & - & ns & 33.7 & - & ns \\
\hline ADgO (GT1a) & 25.7 & - & ns & 24.7 & - & ns & 23.3 & - & ns \\
\hline TNgO (GT4)e & 4.9 & 0.27 & $\star$ & 6.9 & 0.22 & $*$ & 7.3 & 0.24 & $\star$ \\
\hline $\mathrm{ME}$ & \multicolumn{3}{|c|}{$\left(2.0 \times 10^{8}\right)$} & \multicolumn{3}{|c|}{$\left(5.0 \times 10^{8}\right)$} & \multicolumn{3}{|c|}{$\left(5.0 \times 10^{8}\right)$} \\
\hline gO genotype & Mean & Fold & ANOVA & Mean & Fold & ANOVA & Mean & Fold & ANOVA \\
\hline $\mathrm{MEgO}(\mathrm{GT} 5)$ & $\overline{21.6}$ & & - & 5.8 & 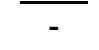 & - & 7 & & - \\
\hline TR(GT1b) & 5.3 & 0.25 & * & 7.1 & - & ns & 3.9 & 0.56 & * \\
\hline $\mathrm{PHgO}(\mathrm{GT} 2 \mathrm{a})$ & 8.0 & 0.37 & * & 7.5 & 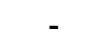 & ns & 2.3 & 0.33 & * \\
\hline TBgO (GT1c) & 15.9 & 0.74 & * & 9.0 & - & ns & 7 & - & ns \\
\hline ADgO (GT1a) & 2.4 & 0.11 & * & 2.4 & - & ns & 3.7 & 0.53 & * \\
\hline $\mathrm{TNgO}$ (GT4) & 5.8 & 0.27 & * & 8.5 & - & ns & 7.4 & - & ns \\
\hline MT & \multicolumn{3}{|c|}{$\left(1.0 \times 10^{8}\right)$} & \multicolumn{3}{|c|}{$\left(2.0 \times 10^{8}\right)$} & \multicolumn{3}{|c|}{$\left(5.0 \times 10^{8}\right)$} \\
\hline gO genotype & Mean & Fold & ANOVA & Mean & Fold & ANOVA & Mean & Fold & ANOVA \\
\hline $\mathrm{MEgO}(\mathrm{GT} 5)$ & $\overline{27.5}$ & - & - & $\overline{63.9}$ & - & - & $\overline{120.9}$ & - & - \\
\hline TR(GT1b) & 28.5 & - & ns & 40.2 & 0.63 & * & 159.4 & - & ns \\
\hline $\mathrm{PHgO}(\mathrm{GT} 2 \mathrm{a})$ & 33.4 & - & ns & 50.4 & - & ns & 222 & 1.84 & * \\
\hline TBgO (GT1c) & 44.6 & 1.6 & * & 66.2 & - & ns & 220.8 & 1.83 & * \\
\hline ADgO (GT1a) & 8.5 & 0.31 & * & 13.4 & 0.21 & * & 23.6 & 0.2 & * \\
\hline TNgO (GT4) & 32.5 & 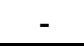 & ns & 61.8 & - & ns & 133.2 & - & ns \\
\hline
\end{tabular}

a. Concentration of cell-free virus stock (genomes $/ \mathrm{mL}$ ) applied to cells.

b. Average pp150 puncta detected by immunofluorescence per cell in 10 microscopy fields; approximately 4 to 6 cells per field.

c. Fold difference in mean pp150 puncta per cell as compared to parental virus. Determined for recombinant viruses that were significantly different $(p \leq 0.05)$ from parental within an experiment. $(-)$ indicates value not calculated.

d. One-way ANOVA with Dunnett's multiple comparisons test comparing each recombinant to the parental. $\left({ }^{*}\right) ; p \leq 0.05$, , (ns); not significant.

e. Bold font indicates recombinant viruses that were significantly different from the parental in the same direction $(>$ or $<)$ in all 3 experiments. 
bioRxiv preprint doi: https://doi.org/10.1101/867234; this version posted January 20,2020 . The copyright holder for this preprint (which was not certified by peer review) is the author/funder, who has granted bioRxiv a license to display the preprint in perpetuity. It is made available under aCC-BY-ND 4.0 International license.

900 Table 3. Binding of parental and heterologous go recombinant HCMV to epithelial cells.

\begin{tabular}{|c|c|c|c|c|c|c|c|c|c|}
\hline $\begin{array}{c}\text { Genotype } \\
\text { Background }\end{array}$ & \multicolumn{3}{|c|}{$\frac{\text { Experiment } 1}{\left.\text { (input }^{a}\right)}$} & \multicolumn{3}{|c|}{$\frac{\text { Experiment } 2}{\text { (input) }}$} & \multicolumn{3}{|c|}{$\frac{\text { Experiment } 3}{\text { (input) }}$} \\
\hline TR & \multicolumn{3}{|c|}{$\left(6.2 \times 10^{7}\right)$} & \multicolumn{3}{|c|}{$\left(7.5 \times 10^{7}\right)$} & \multicolumn{3}{|c|}{$\left(1.0 \times 10^{8}\right)$} \\
\hline gO genotype & Mean $^{b}$ & Fold $^{c}$ & ANOVA $^{d}$ & Mean & Fold & ANOVA & Mean & Fold & ANOVA \\
\hline $\mathrm{TR}(\mathrm{GT} 1 \mathrm{~b})$ & 26.2 & - & - & 41.7 & - & - & 43.7 & - & - \\
\hline $\mathrm{MEgO}(\mathrm{GT5})$ & 35.5 & 1.35 & * & 38.3 & - & ns & 56.8 & - & ns \\
\hline $\mathrm{PHgO}(\mathrm{GT} 2 \mathrm{a})$ & 33.4 & - & ns & 19.3 & 0.46 & * & 61 & 1.4 & * \\
\hline TBgO (GT1c) & 24.1 & - & ns & 35.4 & - & ns & 58.7 & 1.34 & * \\
\hline ADgO (GT1a) & 36.4 & 1.39 & * & 22.2 & 0.53 & 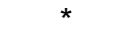 & 36 & - & ns \\
\hline TNgO $(\mathrm{GT} 4)^{\mathrm{e}}$ & 16.2 & 0.62 & * & 18.62 & 0.45 & * & 23.4 & 0.54 & * \\
\hline ME & \multicolumn{3}{|c|}{$\left(2.0 \times 10^{8}\right)$} & \multicolumn{3}{|c|}{$\left(5.0 \times 10^{8}\right)$} & \multicolumn{3}{|c|}{$\left(5.0 \times 10^{8}\right)$} \\
\hline gO genotype & Mean & Fold & ANOVA & Mean & Fold & ANOVA & Mean & Fold & ANOVA \\
\hline MEgO(GT5) & 37.3 & - & - & 18 & - & - & 15 & - & - \\
\hline $\mathrm{TR}(\mathrm{GT} 1 \mathrm{~b})$ & 17.7 & 0.47 & * & 24.9 & - & ns & 10.4 & 0.69 & * \\
\hline $\mathrm{PHgO}(\mathrm{GT} 2 \mathrm{a})$ & 22.3 & 0.6 & * & 23 & - & ns & 9.4 & 0.62 & * \\
\hline TBgO (GT1c) & 34.1 & - & ns & 32.3 & 1.79 & * & 18.6 & - & ns \\
\hline ADgO (GT1a) & 14.4 & 0.39 & * & 11.4 & - & ns & 10.8 & 0.72 & * \\
\hline $\mathrm{TNgO}$ (GT4) & 24.4 & 0.65 & * & 25.9 & 1.44 & * & 14.3 & & ns \\
\hline MT & \multicolumn{3}{|c|}{$\left(1.0 \times 10^{8}\right)$} & \multicolumn{3}{|c|}{$\left(2.0 \times 10^{8}\right)$} & \multicolumn{3}{|c|}{$\left(5.0 \times 10^{8}\right)$} \\
\hline gO genotype & Mean & Fold & ANOVA & Mean & Fold & ANOVA & Mean & Fold & ANOVA \\
\hline MEgO(GT5) & $\overline{33.2}$ & 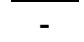 & - & 68 & 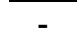 & - & $\overline{236.8}$ & 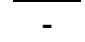 & - \\
\hline TR(GT1b) & 35.3 & - & ns & 46.1 & 0.68 & * & 210.1 & - & ns \\
\hline $\mathrm{PHgO}(\mathrm{GT} 2 \mathrm{a})$ & 46.5 & - & ns & 78 & - & ns & 383.2 & 1.62 & * \\
\hline TBgO (GT1c) & 63.4 & 1.91 & * & 69.6 & - & ns & 238.3 & - & ns \\
\hline ADgO (GT1a) & 16.7 & 0.5 & * & 26.1 & 0.38 & * & 26.6 & 0.11 & * \\
\hline TNgO (GT4) & 44.1 & - & ns & 48.1 & 0.71 & * & 150.9 & 0.64 & * \\
\hline
\end{tabular}

a. Concentration of cell-free virus stock (genomes $/ \mathrm{mL}$ ) applied to cells.

b. Average pp150 puncta detected by immunofluorescence per cell in 10 microscopy fields; approximately 4 to 6 cells per field.

c. Fold difference in mean pp150 puncta per cell as compared to parental virus. Determined for recombinant viruses that were significantly different $(p \leq 0.05)$ from parental within an experiment. (-) indicates value not calculated.

d. One-way ANOVA with Dunnett's multiple comparisons test comparing each recombinant to the parental. $\left(^{*}\right) p \leq 0.05$, (ns) not significant

e. Bold font indicates recombinant viruses that were significantly different from the parental in the same direction $(>$ or $<)$ in all 3 experiments. 


\section{Background} genotype:

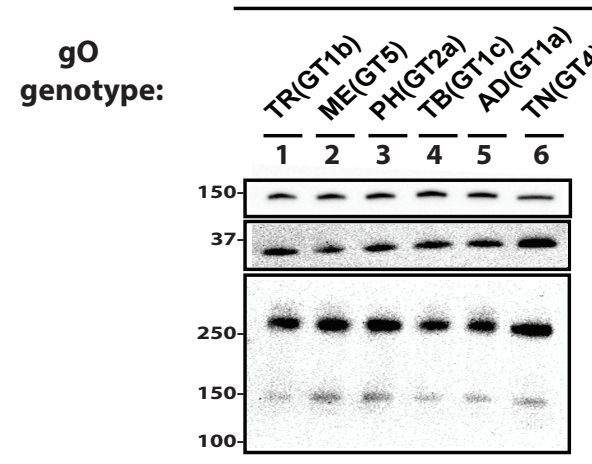

A. TR
B. ME
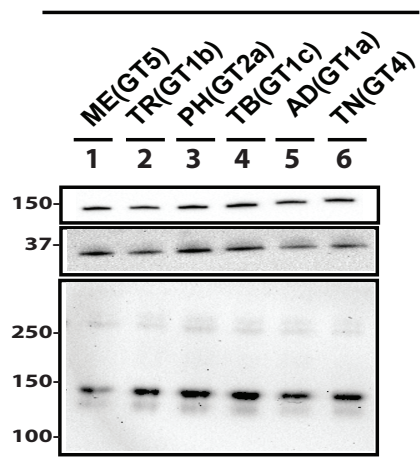

C. MT
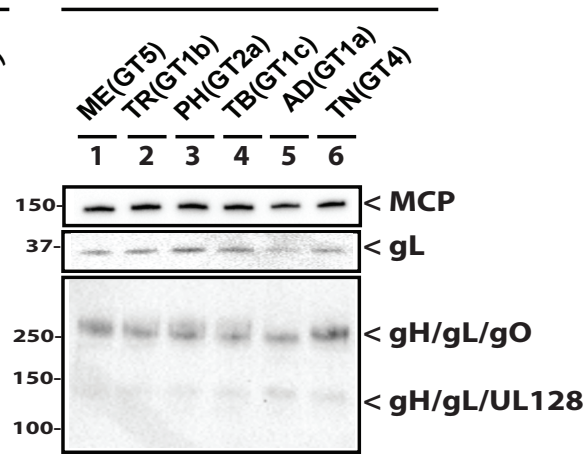


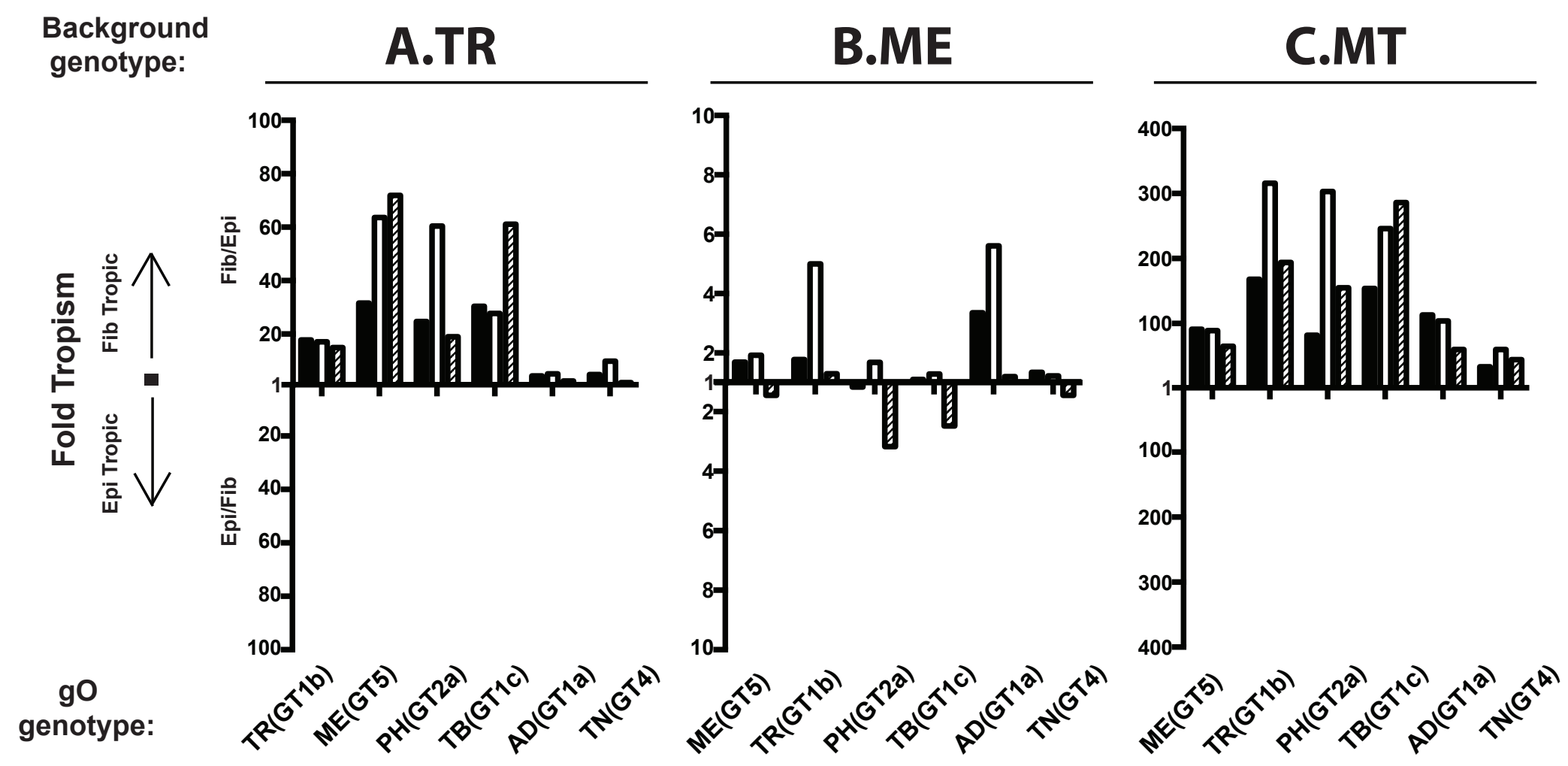




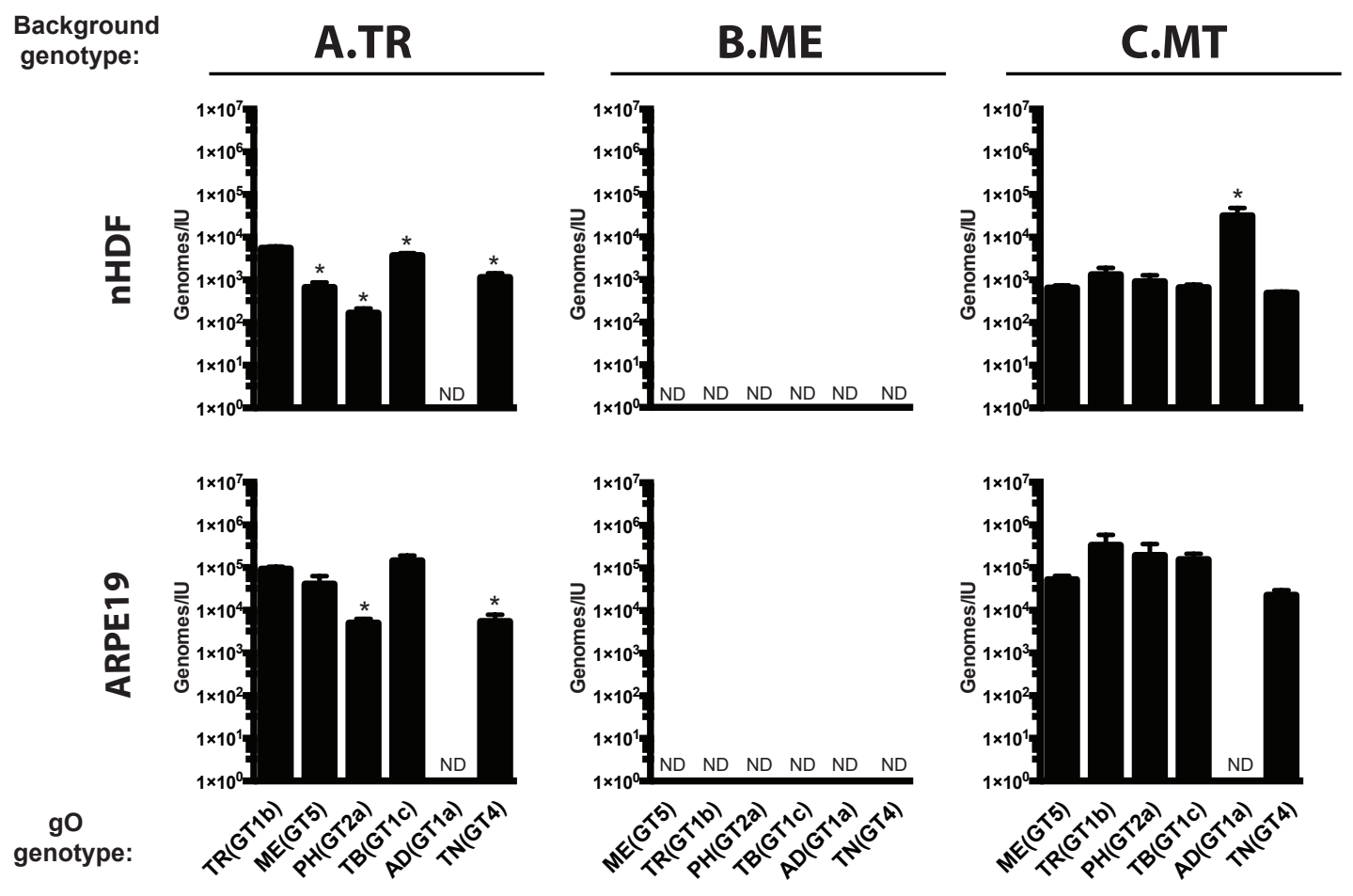


A.

\section{Background} genotype:

go genotype:

gO genotype:

B.
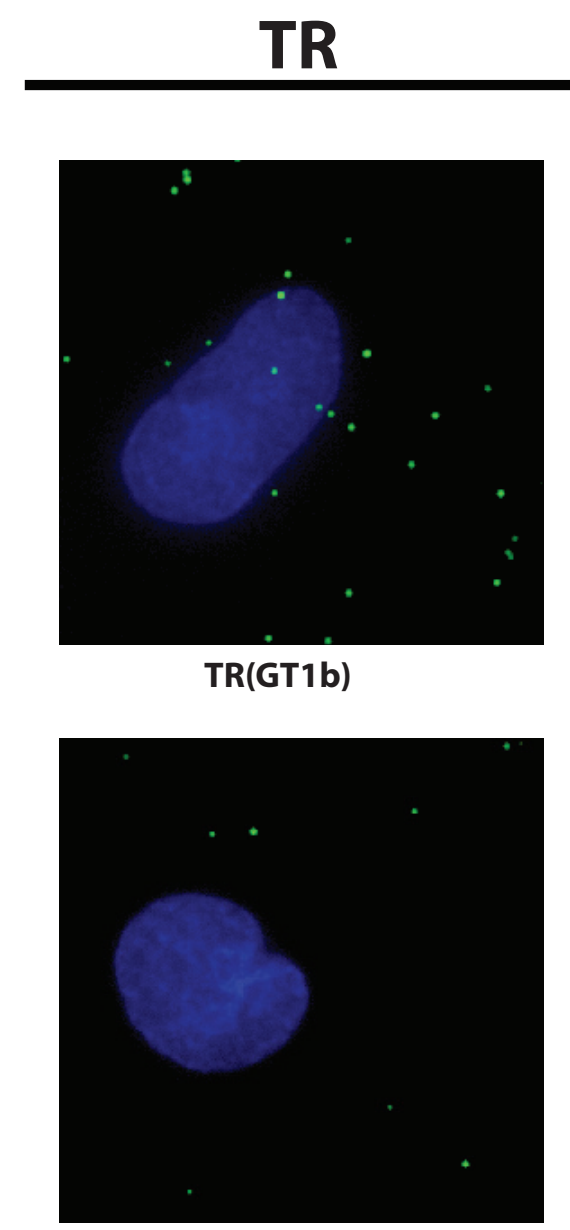

TNgO(GT4)

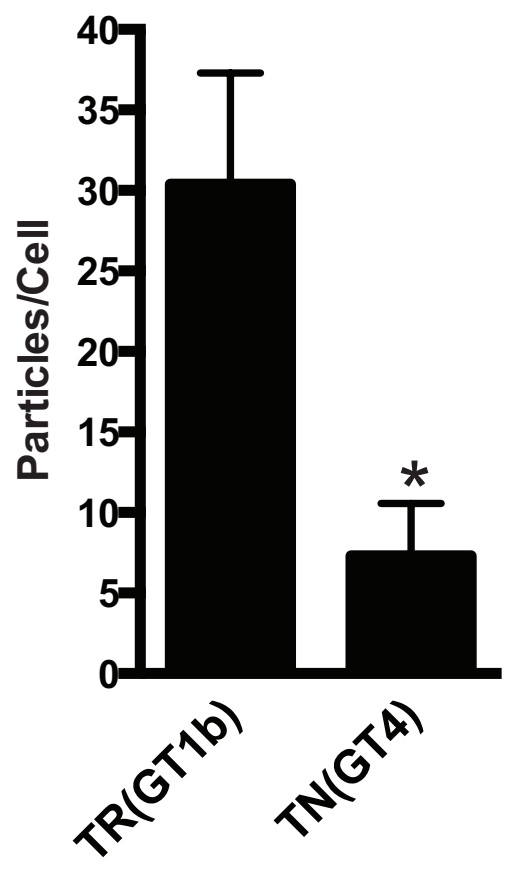

ME

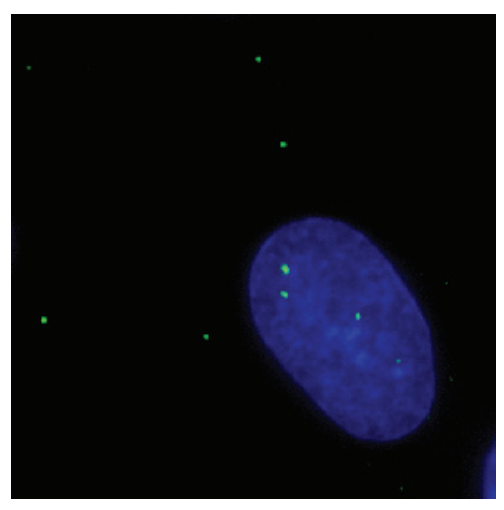

ME(GT5)

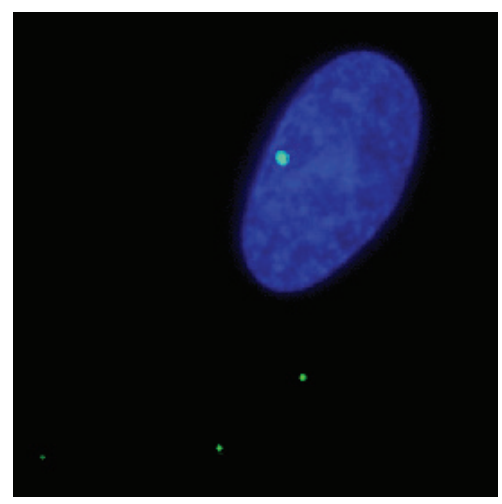

ADgO(GT1a)

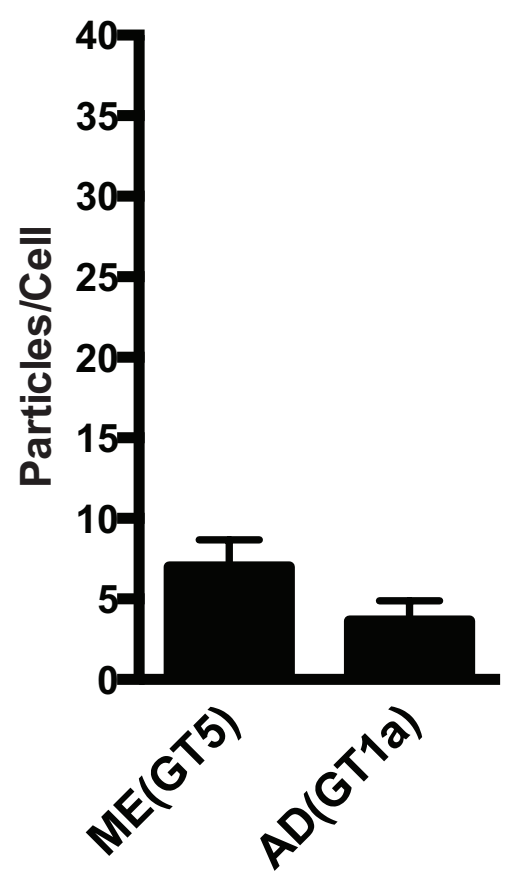

MT

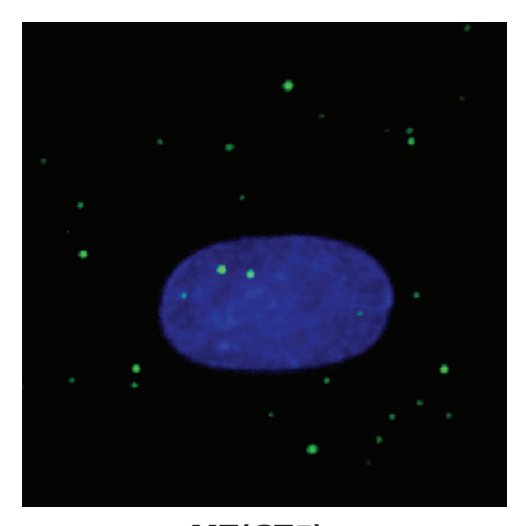

MT(GT5)

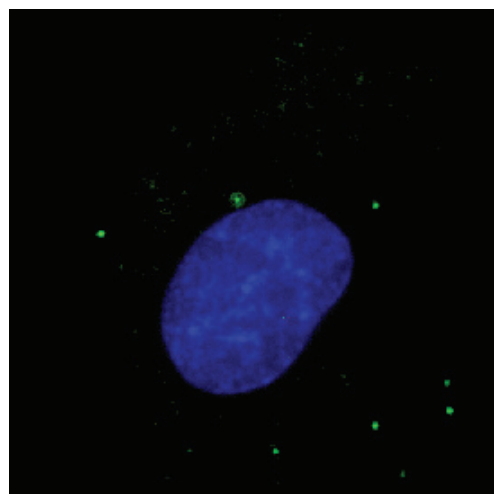

ADgO(GT1a)

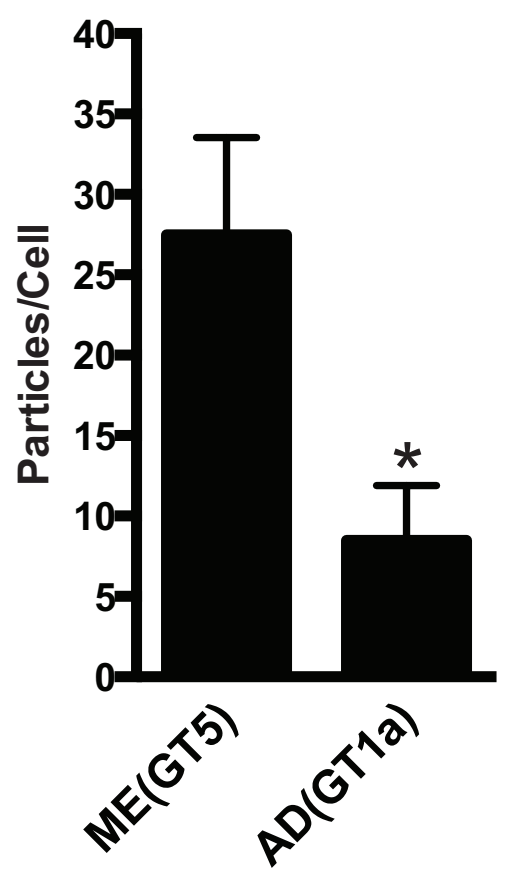


A.

Day3

Day12

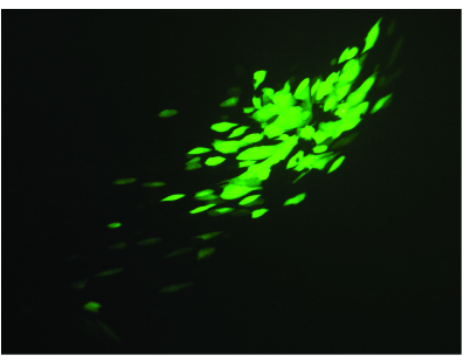

ME
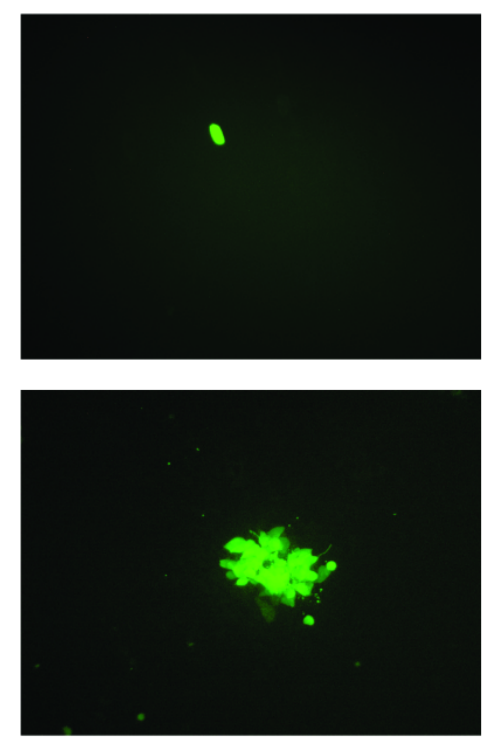

MT
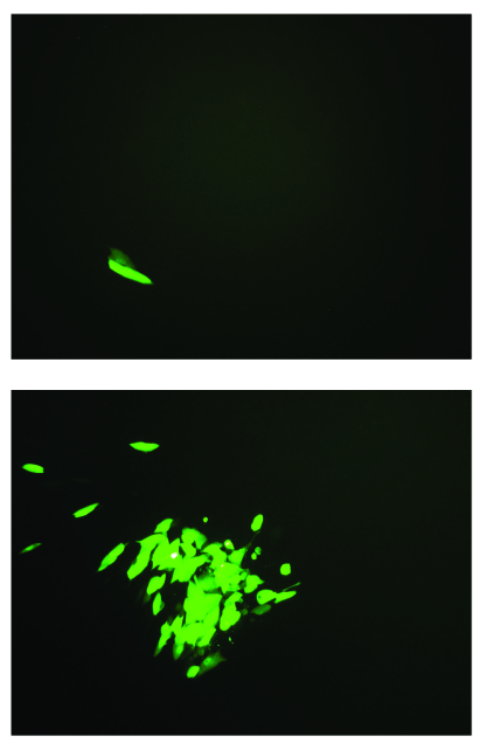

B.

\section{Background} genotype:

go
genotype:
B.TR
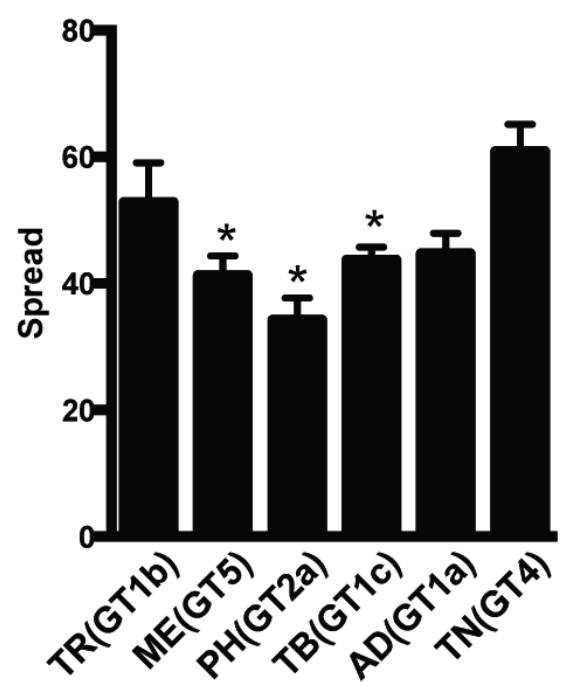

C.ME
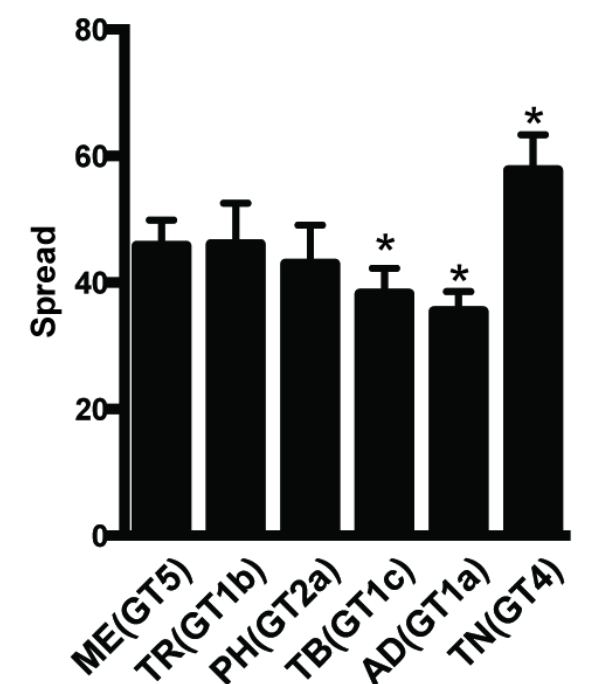

D.MT
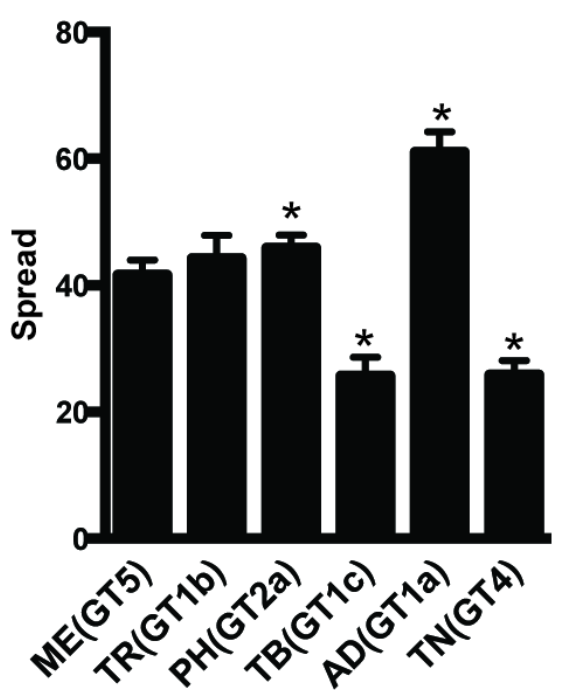

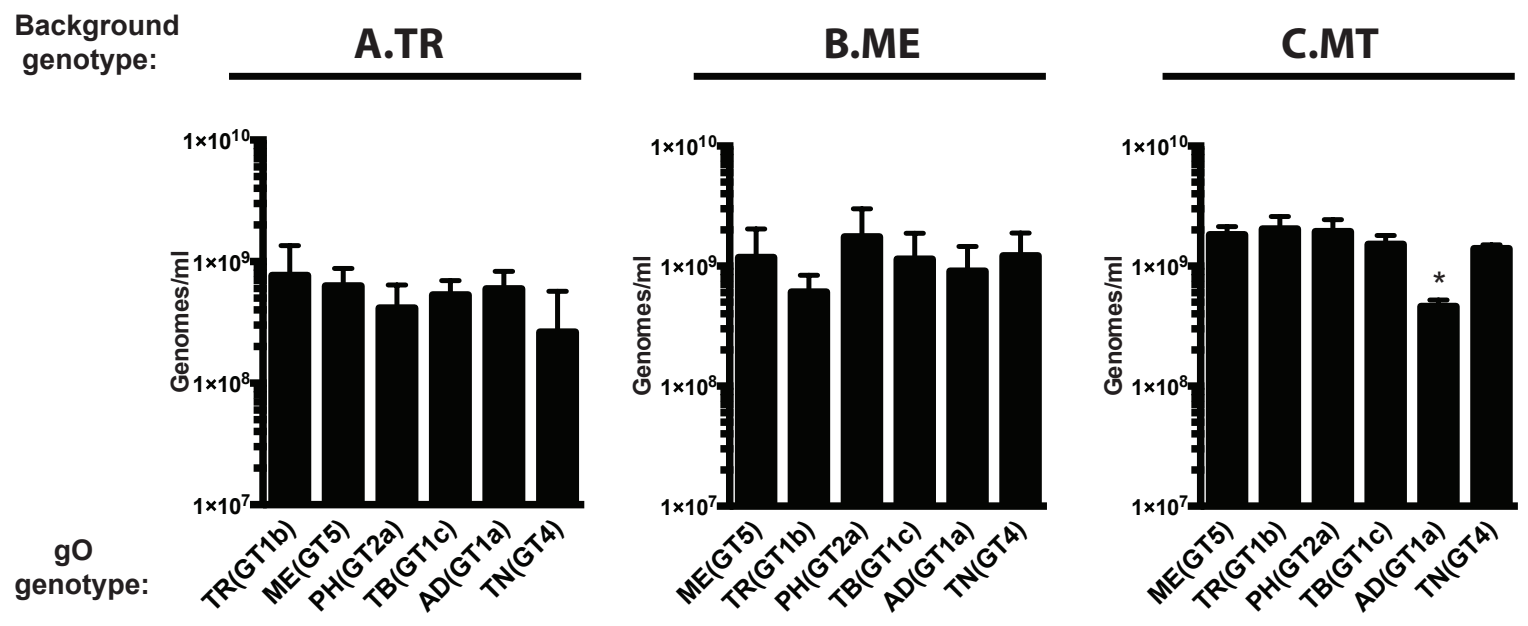


\section{Day3}

TR

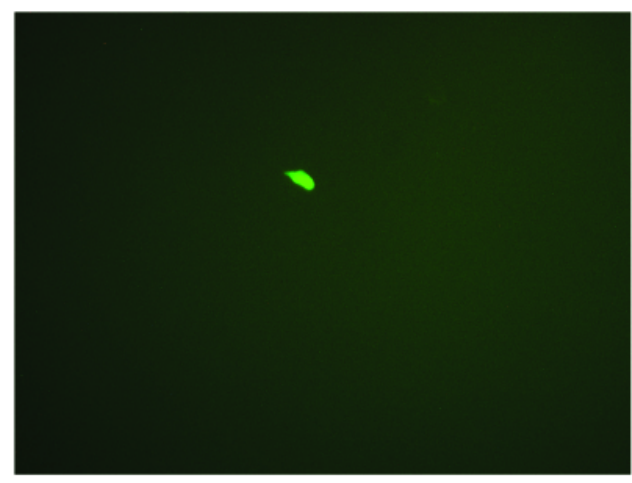

Day12

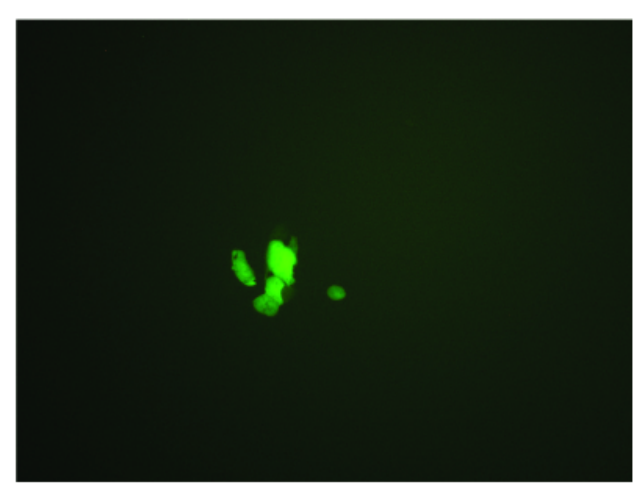

B.

Background genotype:

\section{B.TR}

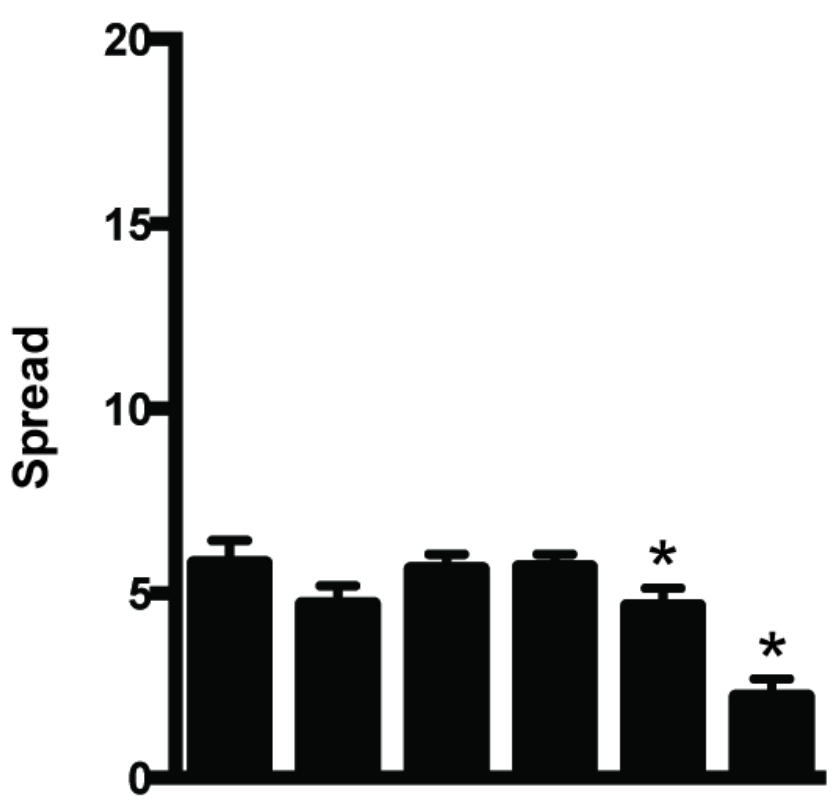

go genotype:

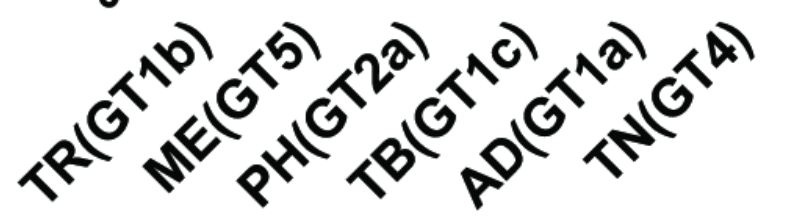

ME
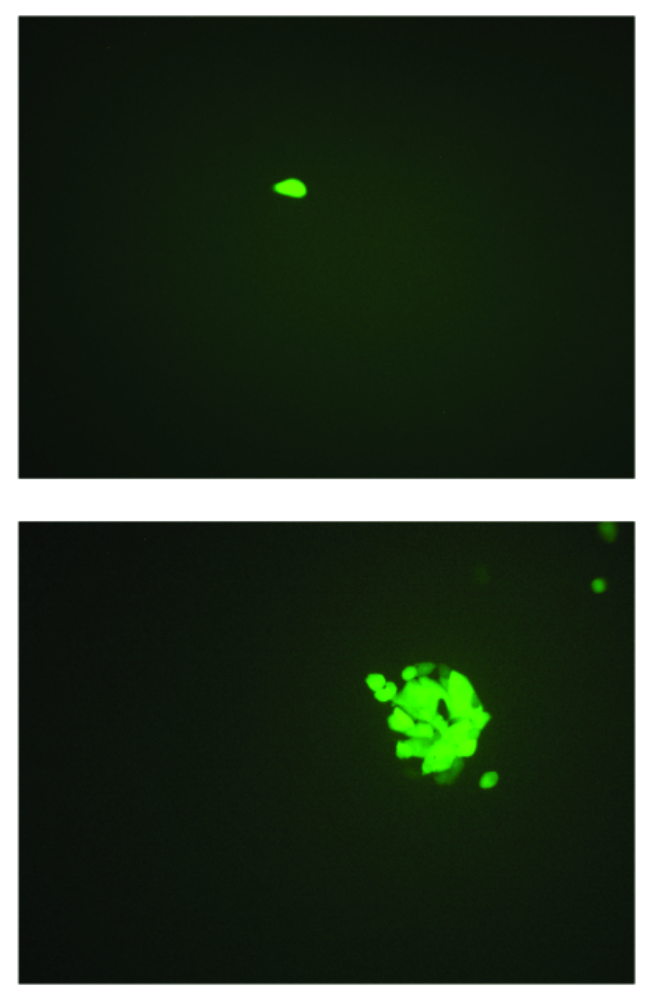

C.ME

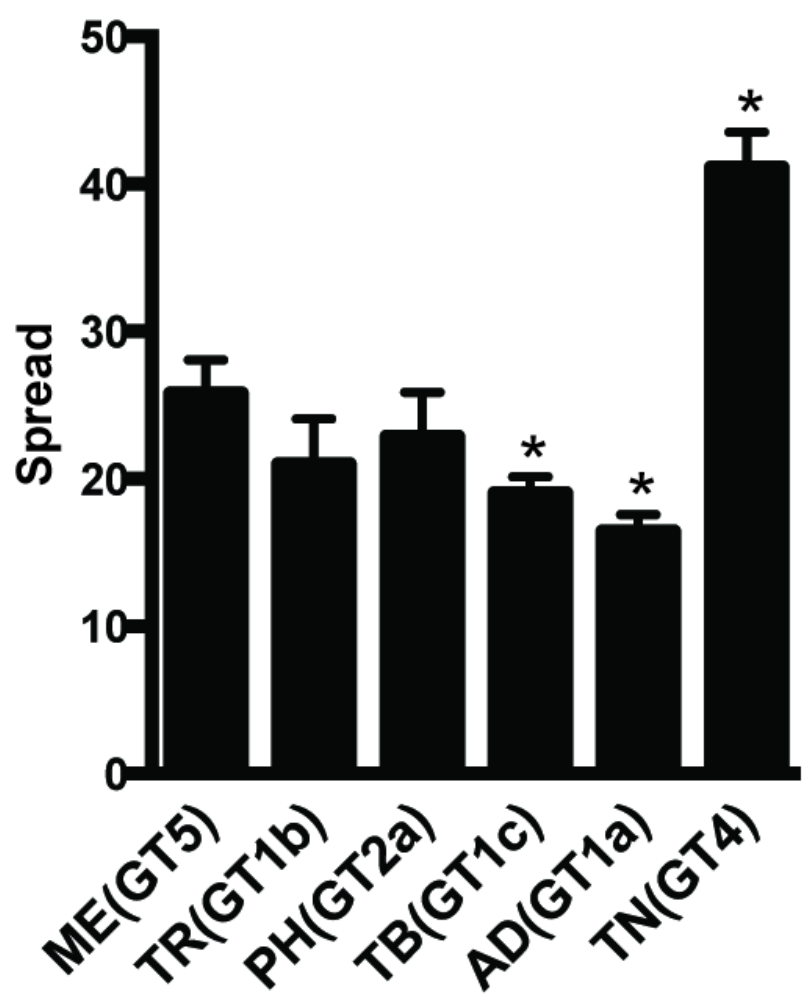




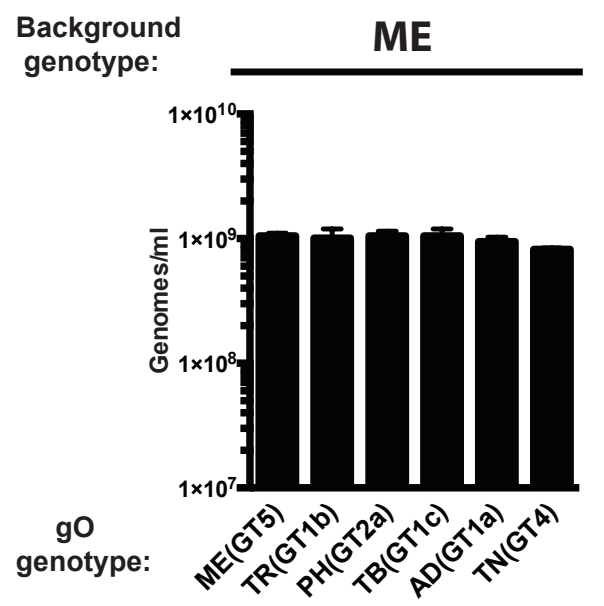


bioRxiv preprint doi: https://doi.org/10.1101/867234; this version posted January 20, 2020. The copyright holder for this preprint (which was not certified by peer review) is the author/funder, who has granted bioRxiv a license to display the preprint in perpetuity. It is made available under

\section{A. nHDF}
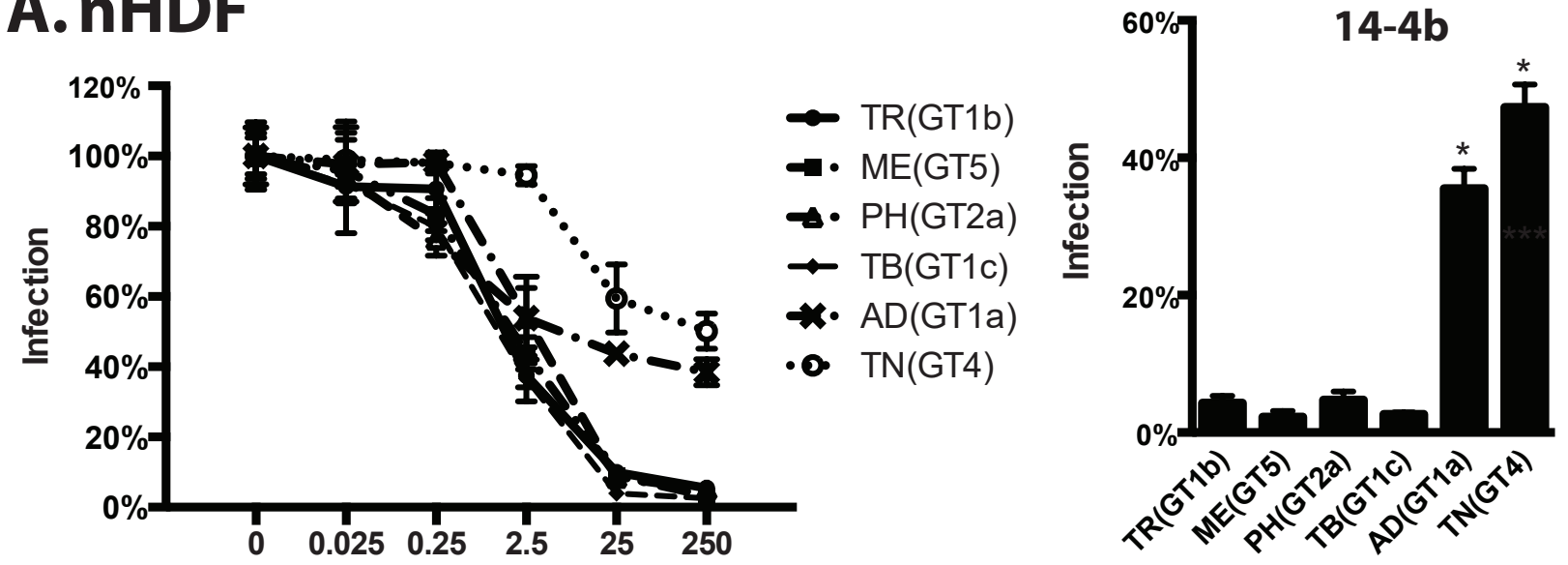

B. nHDF aCC-BY-ND 4.0 International license.
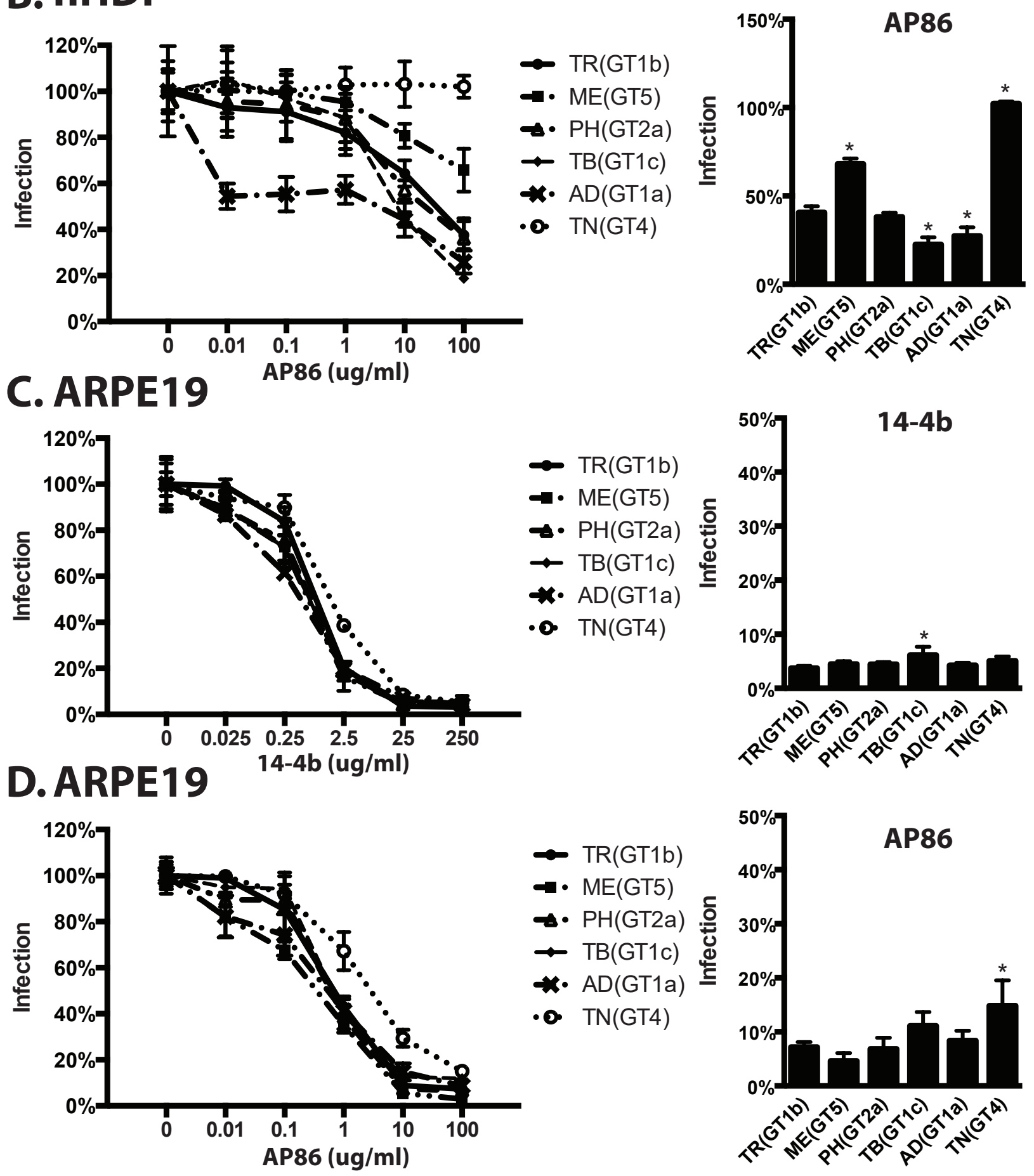


\section{A.nHDF}
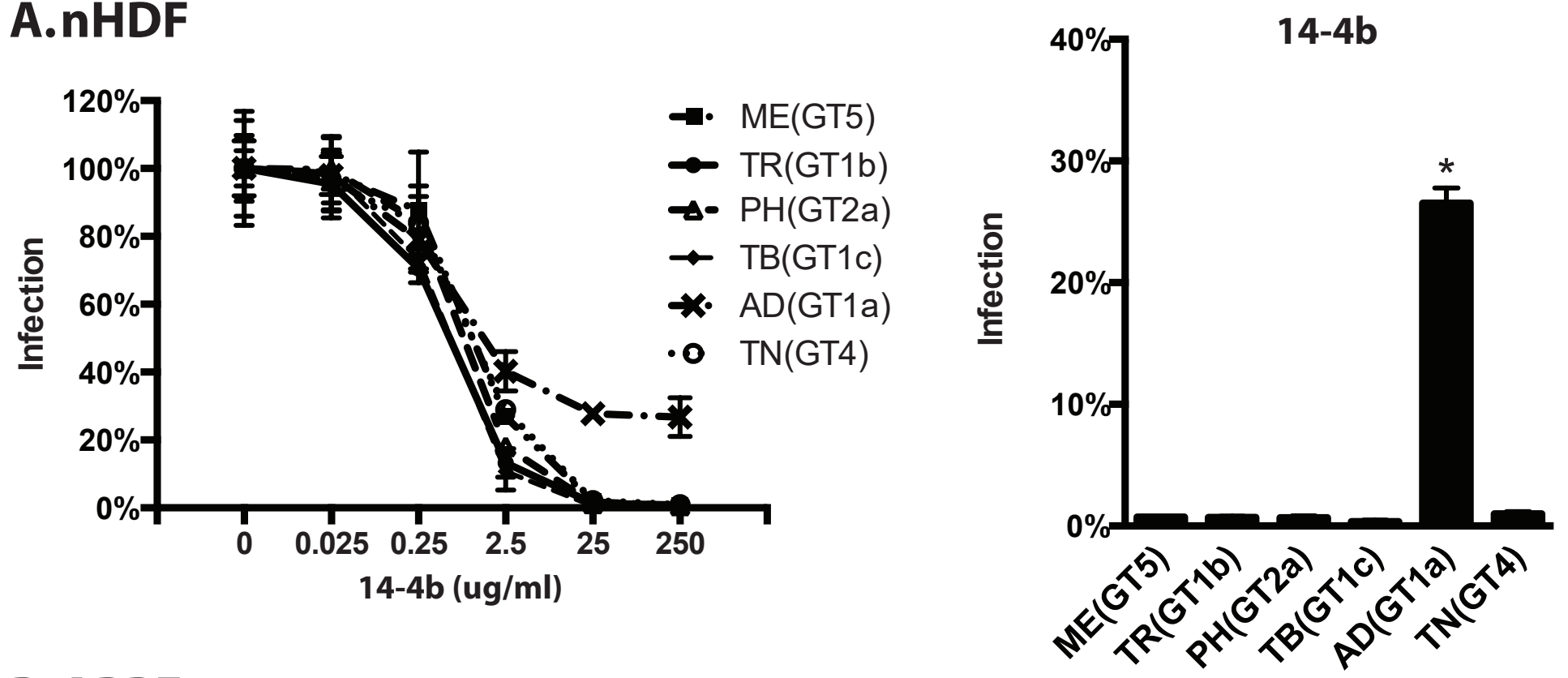

\section{B. ARPE 19}
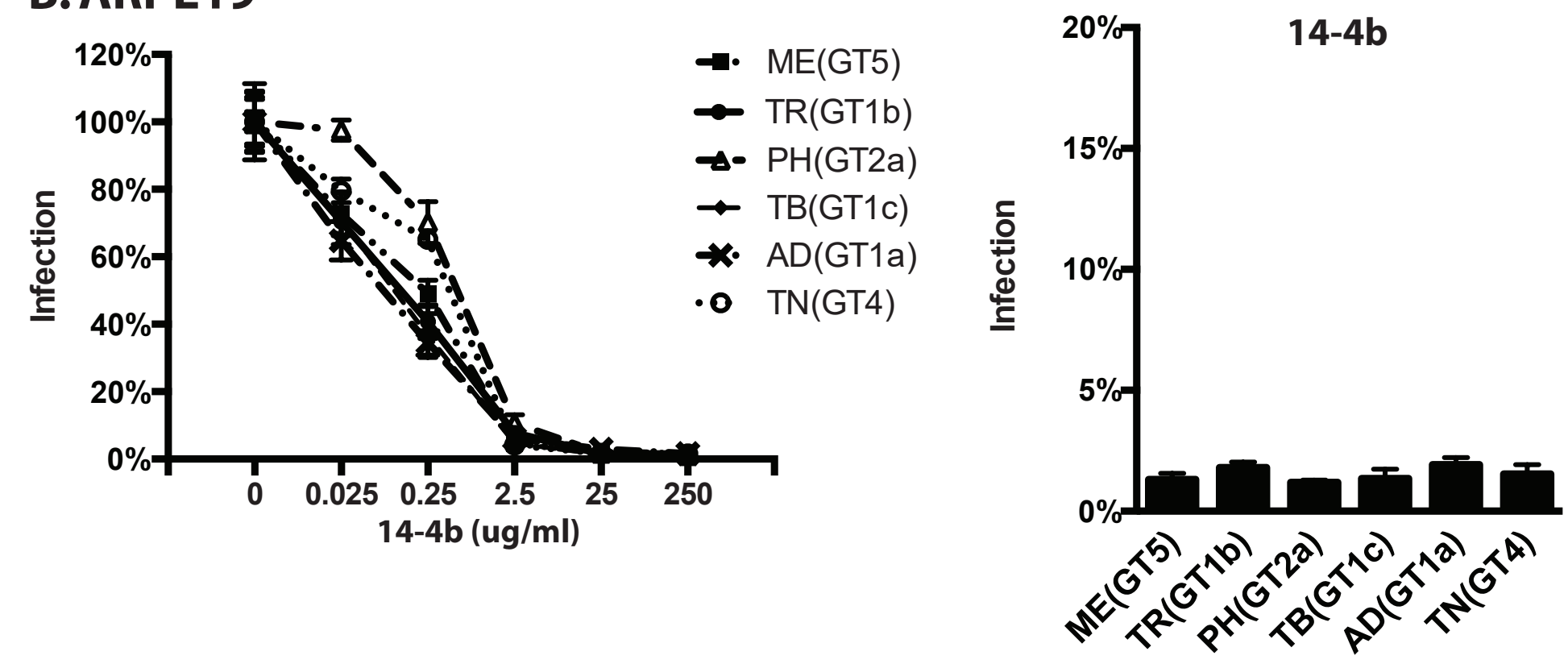


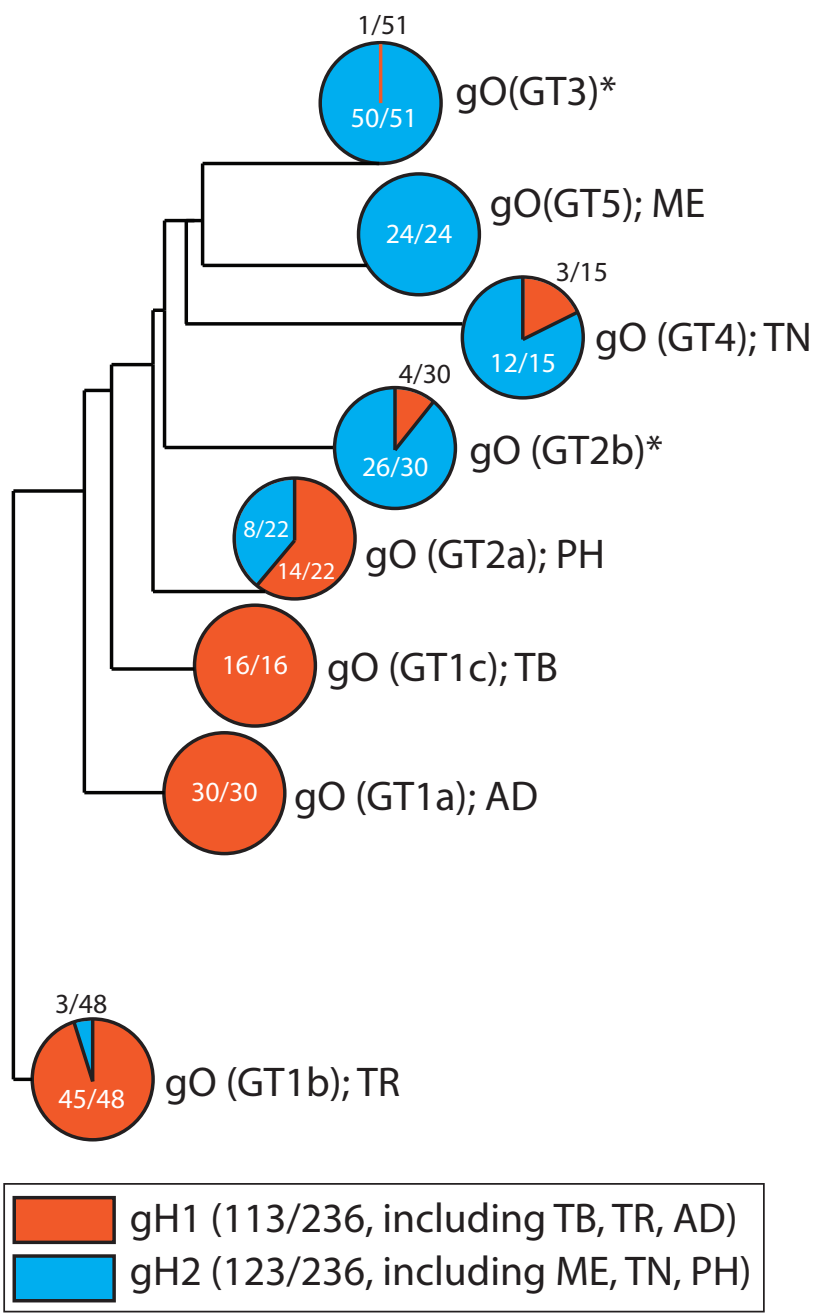

